\title{
Solar energy storage in German households: profitability, load changes, and flexibility
}

Thomas Kaschub $^{1, \mathrm{a}}$, Patrick Jochem ${ }^{\text {a }}$, Wolf Fichtner ${ }^{\text {a }}$

${ }^{1}$ corresponding author, Tel.: +49 721 608-44559, E-Mail: kaschub@kit.edu

${ }^{\text {a }}$ Chair of Energy Economics, Institute for Industrial Production (IIP), Karlsruhe Institute of Technology (KIT), Building 06.33, Hertzstr. 16, D-76187 Karlsruhe, Germany

Highlights

- Domestic photovoltaics (PV) and storage systems are techno-economically analyzed.

- PV \& storage are profitable in the medium term due to high self-consumption rates.

- Controlled electric vehicle charging improves load flexibility and self-generation.

- External procurement of electricity drastically changes and decreases to 48-58\%.

- Dynamic tariffs e. g. with load limits or demand charges incentivize load shifting.

\section{Abstract}

The developments of battery storage technology together with photovoltaic (PV) roof-top systems might lead to far-reaching changes in the electricity demand structures and flexibility of households. The implications are supposed to affect the generation mix of utilities, distribution grid utilization, and electricity price. Using a techno-economic optimization model of a household system, we endogenously dimension PV system and stationary battery storage (SBS). The results of the reference scenario show positive net present values (NPV) for PV systems of approx. 500-1,800 EUR/kW $\mathrm{k}_{\mathrm{p}}$ and NPV for SBS of approx. 150-500 EUR/kWh. Main influences are the demand of the households, selfconsumption rates, investment costs, and electricity prices. We integrate electric vehicles (EV) with different charging strategies and find increasing NPV of the PV system and self-consumption of approx. $70 \%$. With further declining system prices for solar energy storage and increasing electricity prices, PV systems and SBS can be profitable in Germany from 2018 on even without a guaranteed feed-in tariff or subsidies. Grid utilization substantially changes by households with EV and PV-SBS. We discuss effects of different incentives and electricity tariff options (e. g. load limits or additional demand charges). Concluding, solar energy storage systems will bring substantial changes to electricity sales.

\section{Keywords}

demand flexibility; optimization model; tariff design; electric vehicles; controlled charging; battery storage profitability

\section{Abbreviations}

CHP - combined heat and power; EEG - (Erneuerbare Energien Gesetz) Renewable Energy Act; EV electric vehicle; EV2H - electric vehicle to home; NPV - net present value; PV - photovoltaics; RMSD - root-mean-square deviation; SBS - stationary batteries system; SoC - state of charge; ToU - time of use; UoSC - use of system charge 


\section{Introduction}

It is the declared objective of the United Nations to drastically reduce greenhouse gas emissions in the future decades (United Nations, 2015). This requires comprehensive changes especially in the energy and transport sector. In both sectors one key to reach this objective is to improve energy efficiency and switch to carbon-free technologies.

Among other sources, decentralized electricity generation by solar power with photovoltaic (PV) systems penetrated the German market successfully during the last two decades. About one and a half million PV systems were installed until 2014 (BSW, 2014). This was possible with a feed-in tariff (FIT) guaranteed by the renewable energy law (EEG, 2014). This guaranteed FIT for PV feed-in decreased during the last years and grid parity for household customers in Germany was achieved in 2012 already (Wirth, 2015). The FIT is going to be eliminated in some years. This development incentivizes increase in domestic self-consumption ${ }^{1}$, which leads to a decreasing electricity demand from the grid and increasing electricity feed-in with high simultaneousness.

The reduction of greenhouse gas emissions in the transport sector is currently focusing on the electrification of passenger cars (Jochem et al., 2015). Technological developments and falling prices of large-scaled batteries (Nykvist and Nilsson, 2015) are accelerating this development. Worldwide the share of electric vehicles (EV) increases, however, still at low levels (IEA, 2015). These EV cause an additional electricity demand in combination with a high charging power demand to households (Jochem et al., 2014). Depending on the charging strategy and implementation, this demand could be shifted in time and charging power could be limited. With falling prices for large-scaled batteries, also stationary batteries systems (SBS) come into focus. In Germany until 2016, in a first market phase with about 34,000 sold units and falling prices by about $18 \%$ per year were observed (Kairies et al., 2016). Such systems bring further flexibility into the demand side. But the profitability is not yet clear.

Based on these outlines, it seems to be likely that the electricity demand will change drastically, if technologies like EV and PV-SBS enter the mass market. There might already be millions of EV and households with PV-SBS in a few years from now. Consequently, these households will drastically change external procurement of electricity and will have high feed-in peaks during noon. Such households might have a negative net external procurement of electricity within a year - but with high fluctuations. This might lead to a game changer due to the following developments: Decreasing electricity sales by utility companies and decreasing peak-load prices at spot market due to massive mid-day PV power feed-in lead to further decreasing revenues; increasing energy prices for household customers due to increasing shares for network charges and surcharges might accelerate this development. We are therefore analyzing the question, whether today's pricing schemes in Germany are appropriate for this probable future and which adjustments appear useful. Consequently, we first analyze the profitability of the systems in order to obtain an insight into system sizing, market potential, and the corresponding impact on the load. In addition, new incentives to control the demand side might be necessary.

In this contribution we are focusing on the profitability of PV-SBS for different households with EV and show the corresponding impact on electricity demand. For this purpose, we developed a technoeconomic optimization model (mixed integer programming) of a household with the mentioned

\footnotetext{
${ }^{1}$ The self-consumption rate is the PV electricity production, which is self-consumed in the household, divided by the complete electricity production by the PV system.
} 
applications. Using this model, we evaluate 225 households and discuss the influence of different pricing schemes and give political advice for future adjustment of electricity pricing.

The structure of the paper is as follows. In chapter 2 we give a short literature review. In the following chapter 3 we outline the developed model, the underlying technologies and data as well as a scenario overview. The subsequent chapter 4 presents all results for the PV-SBS (section 4.1) including the impact of integrating EV (section 4.2). The influence of several scenarios on the load is given in section 4.3 and further aspects in section 4.4. We conclude the results by sensitivity analyses in section 4.6. Chapter 5 comprehensively discusses our results and the implications for the German electricity sector. Chapter 6 concludes our analysis and gives comprehensive policy recommendations.

\section{Literature review}

In recent years, literature on the issue of combining PV and SBS in households increased significantly. These publications examine the integration of PV and SBS in different applications, countries, and with different methods. Komiyama and Fujii (2014) show a massive potential for integrating PV systems in Japan, whereas decentralized storage of electricity from PV in households currently is not profitable in most countries (Dufo-Lopez and Bernal-Augustin, 2015; McHenry, 2012; Zucker and Hinchliffe, 2014). The situation improves when including the grid and market perspective. Here, SBS provide grid services and grid congestions are prevented (Rudolf and Papatergiou, 2013). In some cases, SBS in combination with national FIT already today lead to profitable applications (Ratnam et al., 2015; Schmiegel and Kleine, 2014; Bruch and Müller, 2014). Hence, the economic success of the first installations on the market strongly depends on the definition of parameters.

An increasing market penetration of EV and their charging demand will further increase the electricity demand by households, which has a positive effect on the economic value of the PV system. Simultaneously, bottlenecks in the grid might be increased, if the charging process is not sufficiently controlled (Babrowski et al., 2014; Weiller, 2011). The charging strategies might lead to different levels of battery degradation. For the current battery technology, lifetime-extending charging e. $g$. with battery cycling at medium state of charge (SoC) seems to be economically advantageous for vehicle owners rather than a purely arbitrary objective on electricity markets (Lunz et al., 2012). From the system perspective, however, vehicle-to-grid (V2G) concepts facilitate in principle the integration of electricity from renewables and, therefore, might reduce overall system costs (Loisel et al., 2014).

In general, deterministic optimization models (Erdinc, 2014; Kanngiesser, 2013) or simulation models (Dufo-Lopez and Bernal-Augustin, 2015; McHenry, 2012) are used. Uncertainties like price or tariff developments or weather effects are addressed either by a sensitivity analysis (Komiyama and Fujii, 2014), by integrating probabilistic approaches (ElNozahy et al., 2015) or by approaches to minimize forecast uncertainties (Ghofrani et al., 2014; Moshövel et al., 2015). Not in all cases are the uncertainties of relevance to the results (Cai et al., 2013).

Both EV charging and use of SBS increase the load-shifting potentials of households substantially. An inclusion of these potentials in the electricity markets by demand response mechanisms has already been analyzed by several studies from the household perspective (Erdinc, 2014; Sandoval and Leibundgut, 2014; Yoza et al., 2014) and from the utility perspective (Zhao et al., 2013). However, most of these studies neglect the investments in infrastructure for enabling demand response measures. 
Investigating these costs leads to more pessimistic results (Gottwalt et al., 2011; Lyon et al., 2012). Nevertheless, in the future electricity system these technologies might be an alternative to grid capacity enhancements (Poudineh and Jamasb, 2014).

\section{Methodology and data}

\subsection{Model overview}

An integrated analysis of load flexibilities by EV and PV-SBS, including dimensioning and operation of these technologies combined with alternative tariffs, is still missing in literature. Only such an integrated analysis of these systems allows evaluating the influences and its controllability. With this contribution we extend the existing research to reduce this gap. Therefore, we developed an optimization model of a household with EV, PV, and SBS (cf. Figure 1) to determine the optimal solution. The model maximizes the net present value for PV system and SBS, including all expenditures for electricity. The model also endogenously determines the optimal size of the PV system as well as the capacity of SBS. The result implies optimal charging and discharging scheduling for the SBS based on the technical capabilities. A simplified battery degradation model includes both cycle and calendar lifetime of SBS. We evaluate different charging strategies of the EV and evaluate their impact on the net present value (NPV) of the PV system and SBS. We consider neither the personal preferences-driven investment decision in the EV nor the costs of the EV. In our opinion the investment in the $\mathrm{EV}$ is being due to mobility reasons only.

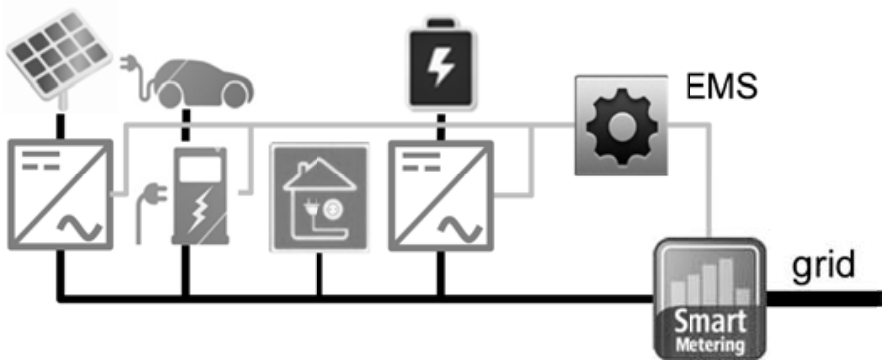

Figure 1: Schematic system overview (black lines for electricity flow and gray for information flows)

The charging of EV and SBS is optimized for a whole year in a quarterly hour time resolution. It is conservatively assumed that the resulting schedule is constant for twenty years, as revenues and costs remain in the same relation over this period. The discounted cash flows allow considering the total expected lifetime of the system. In the following sections we describe the main equations and important restrictions of the model. We indicate variables in bold face. Furthermore, we give data inputs and values of parameters for the reference scenario $(R E F)$. The investment is scheduled for 2018.

Our optimization model with the following described target function and set of constraints is a mixed integer problem (MIP) characterized by up to approx. 750 thousand variables and about 140 thousand discrete (binary) variables. It is implemented in GAMS and solved by the IBM CPLEX solver. 


\subsection{Target function}

The target function (cf. Eq. (1)) maximizes the objective value $(\boldsymbol{O B J})$ as net present value of the regarded system. The $\boldsymbol{O B} \boldsymbol{J}$ includes possible investments in SBS $\left(\boldsymbol{I N} \boldsymbol{V}^{\boldsymbol{S B S}}\right)$ and PV system $\left(\boldsymbol{I N} \boldsymbol{V}^{\boldsymbol{P V}}\right)$ and the sum of annual cash flows $(\boldsymbol{S C F})$.

$$
\max O B J=-I N V^{S B S}-I N V^{P V}+S C F
$$

The investment of the SBS (INV $\left.\boldsymbol{V}^{\boldsymbol{S B S}}\right)$ includes three terms: The investment itself, the consideration of calendar aging effect on lifetime, and the remaining value after the period of consideration. The investment is considered as the product of investment costs per unit ( $i n v^{S B S}$ ) and the installed capacity ( $\boldsymbol{C A P} \boldsymbol{P}^{\boldsymbol{S} \boldsymbol{B} \boldsymbol{S}}$, cf. Eq. (2)). Due to aging, the usable capacity at the end of lifetime equals $80 \%$ of the initial life capacity. Therefore, the initial capacity investment has to be increased by dividing by the remaining capacity factor $(R C=0.8)$. In the second term calendar aging is included by a reduced calendar lifetime (CLTred $^{S B S}$, cf. Eq. (11)) according to Lunz et al. (2012). A calendar lifetime $\left(C L T^{S B S}\right)$ of 20 years is assumed (Schmiegel, 2014; Weniger et al., 2014). The lifetime reduction is considered by a partial replacement investment. In case of assuming a shorter lifetime of SBS compared to the period under consideration ( $p o c=20$ years), further reinvestments are considered (e. g. $\left.y_{i n v} \forall Y_{i n v} \in\{0,8,16\}\right)$ in addition to the initial investment $\left(y_{i n v}=0\right)$. In case of a calendar lifetime longer than the period under consideration, the remaining investment value is considered in the third term according to the remaining lifetime $\left(\right.$ CLTrem $\left.^{S B S}\right)$.

$$
\begin{aligned}
\boldsymbol{I N} \boldsymbol{V}^{\boldsymbol{S B S}}=\sum_{y_{i n v} \in Y_{i n v}}\left(\frac{i n v^{S B S}}{R C}\left(\frac{\boldsymbol{C A P}^{S B \boldsymbol{S}}}{(1+i)^{y_{i n v}}}+\frac{\boldsymbol{C L T r e d}^{\boldsymbol{S B S}}}{(1+i)^{y_{i n v}}}\right)\right) \\
-\frac{C L T r e m^{S B S}}{C L T^{S B S}}\left(\frac{i n v^{S B S} \cdot \boldsymbol{C A P}^{S B \boldsymbol{S}}}{(1+i)^{p o c}}\right)
\end{aligned}
$$

By way of illustration we give an example of equation (2) in equation (3). We assume endogenous determined values $\boldsymbol{C A P} \boldsymbol{P}^{S \boldsymbol{S}}=5 \mathrm{kWh}$ and $\boldsymbol{C L T T}_{\boldsymbol{T}} \boldsymbol{d}^{\boldsymbol{S B S}}=0.2 \mathrm{kWh}$. Further parameter values for the example are introduced in section 3.3.2.

$\boldsymbol{I N} \boldsymbol{V}^{\boldsymbol{S B S}}=\frac{500 E U R / k W h}{0.8}\left(\frac{\mathbf{5} \boldsymbol{k W h}}{(1+0.05)^{0}}+\frac{\mathbf{0 . 2} \boldsymbol{k W h}}{(1+0.05)^{0}}\right)=3,250 E U R$

The investment of the PV system $\boldsymbol{I N} \boldsymbol{V}^{\boldsymbol{P V}}$ is the product of investment per unit $\left(i n v_{y}^{P V}\right)$ and installed peak power ( $\boldsymbol{P}^{\boldsymbol{P V} \text {,peak }}$ ) (cf. Eq. (4)). The remaining investment value is again implemented similar to Eq. (2).

$\boldsymbol{I N V ^ { P V }}=i n v^{P V} \cdot \boldsymbol{P}^{P V, p e a k}-\frac{C L T^{P V, r e s}}{C L T^{P V}}\left(\frac{i n v^{P V} \cdot \boldsymbol{P}^{P V, p e a k}}{(1+i)^{\text {poc }}}\right)$

The sum of yearly cash flows $(\boldsymbol{S C F})$ is discounted for each year $y$ with a constant discount rate $(i=$ $5 \% /$ year) (Konstantin, 2009). Power flows are summed up over all time slices $(t \in\{1,2, \ldots, 35040\})$

of the year (with time slice duration $t s d=0.25 h)$. The electricity demand from the grid $\left(\boldsymbol{P}_{\boldsymbol{t}}^{\text {grid,dem }}\right.$ ) is multiplied by household electricity price $\left(p_{y}^{H H}\right)$. We assume $29.5 \mathrm{ct} / \mathrm{kWh}$ for 2014 (BNetzA, 2014) with a constant moderate increase of $+2 \%$ year compared to an increase of $+3 \%$ year in the last 20 years (BMWi, 2015). A price factor $\left(p f_{t}\right)$ is included that is 1 for a single price and varies for dynamic 
pricing (cf. section 3.4). The discharging electricity from EV to household $\left(\boldsymbol{P}_{\boldsymbol{t}}^{\boldsymbol{E V}, \boldsymbol{d i s g}}\right)$ causes additional battery aging. These costs of deterioration are considered $\left(C^{E V, c y}=7.1 \mathrm{ct} / \mathrm{kWh}\right)$ based on the quotient of a battery investment per unit of $500 \mathrm{EUR} / \mathrm{kWh}$ and the total energy turnover over a cycle lifetime of 7,000 equivalent full cycles (cf. section 3.3.2). In order to limit load demand from grid and feed-in power boundaries $(L A)$ are implemented. When these are activated, power loads exceeding these limits $\left(\boldsymbol{P}_{\boldsymbol{t}}^{\text {dem,over }}\right.$ and $\boldsymbol{P}_{\boldsymbol{t}}^{\text {feed,over }}$ ) are penalized with $p^{\text {over }}(10 \mathrm{ct} / \mathrm{kWh})$. Maintenance costs of SBS ( $\left.p^{S B S, m t}\right)$ of only $1 \% /$ year of investment are considered (IE-Leipzig, 2014), as Li-ion batteries are nearly maintenance-free. The feeding of electricity from the house into the grid $\left(\boldsymbol{P}_{\boldsymbol{t}}^{\boldsymbol{P V}, \boldsymbol{g r i d}}\right)$ is compensated by payment of a feed-in price $\left(p_{y}^{P V}=3.5 \mathrm{ct} / \mathrm{kWh}\right)$ that is lower than average power spot market prices over the last years (4.72 ct/kWh, 2005-2013, EEX in Agora, 2013).

$$
\begin{gathered}
\boldsymbol{S C F}=\sum_{y \in Y} \frac{1}{(1+i)^{y}}\left(-t s d \sum_{t \in T}\left(\boldsymbol{P}_{t}^{\text {grid,dem }} \cdot p_{y}^{H H} \cdot p f_{t}+\boldsymbol{P}_{\boldsymbol{t}}^{E V, \text { disg }} \cdot C^{E V, c y}\right.\right. \\
\left.+p^{\text {over }}\left(\boldsymbol{P}_{\boldsymbol{t}}^{\text {dem,over }}+\boldsymbol{P}_{\boldsymbol{t}}^{\text {feed,over }}\right) L A\right)-\left(p^{S B S, m t} \frac{\boldsymbol{C A P}^{S B \boldsymbol{S}}}{R C}\right) \\
\left.+t s d \sum_{t \in T}\left(\boldsymbol{P}_{\boldsymbol{t}}^{P V, \text { grid }} \cdot p_{y}^{P V}\right)\right)
\end{gathered}
$$

In order to analyze the NPV of PV system $\left(\boldsymbol{N P V} \boldsymbol{P}^{\boldsymbol{P V}}\right)$ and SBS $\left(\boldsymbol{N P V} \boldsymbol{V}^{\boldsymbol{S} \boldsymbol{S}}\right)$ separately, we run the optimization three times with the following system setups and resulting objective values:

- Household without PV system and without SBS: $\boldsymbol{O} \boldsymbol{B J}^{\boldsymbol{H} \boldsymbol{H}}$

- Household with PV system, but without SBS: $\boldsymbol{O} \boldsymbol{B J}^{\boldsymbol{H} \boldsymbol{H + P V}}$

- Household with PV system and with SBS: $\boldsymbol{O} \boldsymbol{B J}^{\boldsymbol{H} \boldsymbol{H}+\boldsymbol{P V}+\boldsymbol{S B S}}$

To determine the first objective value $\boldsymbol{O} \boldsymbol{B} \boldsymbol{J}^{\boldsymbol{H} \boldsymbol{H}}$ the target function is simplified (max $\boldsymbol{O B J}=\boldsymbol{S C F}$ ), as both investments for PV system and SBS are not included. The eq. (5) is simplified as well. Only electricity demand from grid is non zero. Furthermore several restrictions are not considered (Eq. (9) to (16)). The NPV can be calculated by the difference of in each case two objective values:

$$
\begin{aligned}
& N P V^{P V}=O B J^{H H+P V}-O B J^{H H} \\
& N P V^{S B S}=O B J^{H H+P V+S B S}-O B J^{H H+P V}
\end{aligned}
$$

Hence, the NPV of the SBS $\left(\boldsymbol{N P V} \boldsymbol{V}^{\boldsymbol{B} \boldsymbol{S}}\right.$ ) results from the difference of the objective value with $\mathrm{HH}+\mathrm{PV}+\mathrm{SBS}$ and $\mathrm{HH}+\mathrm{PV}$ (cf. Eq. (7)). The difference between the objective value with $\mathrm{HH}+\mathrm{PV}$ and without PV gives the $\boldsymbol{N} \boldsymbol{P V} \boldsymbol{P V}$ (cf. Eq. (6)).

\subsection{Set of constraints and specifications}

In the following subsections we explain important specifications and constraints for the components of the regarded system (cf. Figure 1). 


\subsubsection{Household load and photovoltaic system}

The household load $\left(P_{t}^{H H}\right)$ is an input which is an empirically metered household load curve of a whole year ${ }^{2}$. The investment costs of small PV systems (incl. panels, inverter, and installation) in Germany significantly declined in the last years (2006 to 2012) by about $16 \%$ per year (BSW, 2014). Recently, the investment costs for PV systems were more stable and the decline slowed down. The average investment costs in 2014 were about $1.6 \mathrm{EUR} / \mathrm{W}_{\mathrm{p}}$ with $4 \%$ /year price reduction (based on prices from Q4/2012 to Q1/2014; BSW, 2014). This includes all PV system parts, whereas the inverter has a share of about 0.2 to $0.3 \mathrm{EUR} / \mathrm{W}_{\mathrm{p}}(\mathrm{BMU}, 2011)$. In the time period under consideration, we assume that there will be no tariff for PV feed-in according to the German Renewable Energy Act (EEG), but $3.5 \mathrm{ct} / \mathrm{kWh}$ market-based earnings over all periods. This is a rather conservative assumption, as it is below current market prices at the European Energy Exchange (EEX). Therefore, we can evaluate the profitability of the PV system investment independently of feed-in subsidies. Solar radiations and temperatures are given by test reference years (TRY) of Germany's National Meteorological Service (DWD, 2004). TRY are based on historical data and represent a common year according to long-year average values and a defined weather region (here region 12). We also include the temperature dependence, elevation (ref. $30^{\circ}$ ), and azimuth angle (ref. $0^{\circ}$, south) (Quaschning, 2013) of the PV system. As for the whole system, we assume perfect foresight and predictability also for the PV output and neglect uncertainties.

The power balance of the household includes all demands and supplies within the system boundaries (cf. Figure 1 and Eq. (8)). This includes conventional loads of household $\left(P_{t}^{H H}\right)$, SBS charging $\left(\boldsymbol{P}_{\boldsymbol{t}}^{S B S, \boldsymbol{c h g}}\right)$, and EV charging $\left(\boldsymbol{P}_{\boldsymbol{t}}^{\boldsymbol{E V}, \boldsymbol{c h g}}\right)$. In case of uncontrolled instant charging of the vehicle $\left(\boldsymbol{P}_{\boldsymbol{t}}^{E V, \boldsymbol{c h g}}\right)$ equals $P_{t}^{E V, \text { chg,strt }}$ divided by $\eta^{E V}$. For each time step, the load on the left side of Eq. (8) has to be equal to PV-generated self-consumption $\left(\boldsymbol{P}_{\boldsymbol{t}}^{\boldsymbol{P V}, \boldsymbol{s e l f}}\right)$, electricity demand from grid $\left(\boldsymbol{P}_{\boldsymbol{t}}^{\boldsymbol{g r i d}, \boldsymbol{d e m}}\right)$, power from SBS $\left(\boldsymbol{P}_{\boldsymbol{t}}^{\boldsymbol{S B S}, \boldsymbol{d i s} \boldsymbol{g}}\right)$, and discharging from $\mathrm{EV}\left(\boldsymbol{P}_{\boldsymbol{t}}^{\boldsymbol{E V}, \boldsymbol{d i s} \boldsymbol{g}}\right)$.

$P_{t}^{H H}+P_{t}^{S B S, \text { chg }}+P_{t}^{E V, c h g}=P_{t}^{P V, \text { self }}+P_{t}^{g r i d, d e m}+P_{t}^{S B S, \text { disg }}+P_{t}^{E V, \text { disg }} \quad \forall t \in T$

The power balance of the PV system in Eq. (9) guarantees that all PV production $\left(\boldsymbol{P}_{\boldsymbol{t}}^{\boldsymbol{P V}}\right)$ is selfconsumed $\left(\boldsymbol{P}_{t}^{P V, \text { self }}\right)$ or fed into the power grid $\left(\boldsymbol{P}_{\boldsymbol{t}}^{\boldsymbol{P V}, \boldsymbol{g r i d}}\right)$. If the feed-in exceeds a certain power threshold ( $\boldsymbol{P}_{\boldsymbol{t}}^{\boldsymbol{P V}, \text { lim }}$, e. g. $50 \%$ of installed capacity), the feed-in is curtailed. This limitation of PV feed-in is considered according to the current EEG (2014) by activating the throttling limit binary parameter PVLA. The second implemented measure is a penalty fee $(10 \mathrm{ct} / \mathrm{kWh})$, if the feed-in limit is exceeded $\left(\boldsymbol{P}_{\boldsymbol{t}}^{\text {feed,over }}\right)$. It can be activated by binary parameter $(L A)$.

$\boldsymbol{P}_{t}^{P V}=\boldsymbol{P}_{t}^{P V, \text { self }}+\boldsymbol{P}_{t}^{P V, \text { grid }}+\boldsymbol{P}_{t}^{\text {feed,over }} \cdot L A+\boldsymbol{P}_{t}^{P V, \text { lim }} \cdot P V L A \quad \forall t \in T$

\subsubsection{Stationary battery system}

For the SBS as well as for the EV battery, a generic or stylized Li-ion based battery is represented in the model. Their prices are expected to decrease in the following years (Nykvist and Nilsson, 2015; Tesla, 2015). As stationary application has lower requirements than mobile applications, we assume that prices for SBS converge to those for EV. But the market for SBS still is in an early stage. For the

\footnotetext{
${ }^{2}$ The metered load curves are taken from the internal database of our Institute for Industrial Production (IIP) for households with constant energy tariff.
} 
investment in SBS, we use $500 \mathrm{EUR} / \mathrm{kWh}$ in 2018 , which is above former EV market prices (IEA, 2013) and the lowest battery price for current SBS (Tesla, 2015). The assumed price for SBS includes all system components, such as battery cell packs with management system or inverter. The inverter has a high share in the total price, which today is about $180 \mathrm{EUR} / \mathrm{kW}_{\mathrm{p}}$ (Fuhs 2015). In the first market overview of 2012 for SBS, Fuhs (2012) determines an average calendar lifetime for SBS of 19.7 years and 5,000 full cycles. Partial cycles are less degenerating for Li-ion batteries (Kalhammer et al., 2007). Therefore, we assume 7,000 equivalent full cycles and 20 years calendar lifetime for our system in 2018.

The balance Eq. (10) for SBS equals the energy content of the battery $\left(\boldsymbol{E}_{\boldsymbol{t}}^{\boldsymbol{S B S}}\right)$ to the battery content of the previous time slice $\left(\boldsymbol{E}_{\boldsymbol{t}-1}^{\boldsymbol{S B} \boldsymbol{S}}\right)$, including all differences by charging $\left(\boldsymbol{P}_{\boldsymbol{t}}^{\boldsymbol{S B S}, \boldsymbol{c h} \boldsymbol{g}}\right)$ and discharging $\left(\boldsymbol{P}_{\boldsymbol{t}}^{S B S, \boldsymbol{d i s g}}\right)$. Charging energy comes from grid or from PV (cf. Eq. (8)). The charging efficiency $\left(\eta^{S B S}\right)$ is assumed to be 0.94 (Quaschning, 2013). In addition, self-discharging $\left(\boldsymbol{P}_{\boldsymbol{t}}^{\boldsymbol{S B S}, \boldsymbol{s e l f d i s g}}\right)$ of $2 \%$ per month is considered. The initial value $E_{t_{0}}^{S B S}$ is given separately.

$\frac{E_{t}^{S B S}}{t s d}=\frac{E_{t-1}^{S B S}}{t s d}+\boldsymbol{P}_{t}^{S B S, c h g} \cdot \eta^{S B S}-\frac{\boldsymbol{P}_{t}^{S B S, \text { disg }}}{\eta^{S B S}}-\boldsymbol{P}_{t}^{S B S, \text { selfdisg }}$ $\forall t \in T$

The calendar lifetime is reduced for high SoC according to Lunz et al. (2012). We consider this aspect by a simplified interrelationship in Eq. (11). It is a linear function derived from Lunz et al. (2012), which states that an always fully charged SBS reduces its whole lifetime by about one third (every 8,760 hours of the year). The reduced calendar lifetime $\left(\boldsymbol{C L T T} \boldsymbol{C A}^{\boldsymbol{S B S}}\right.$ ) due to the average energy stored $\left(\boldsymbol{E}_{\boldsymbol{t}}^{\boldsymbol{S B S}}\right.$ ) during each time step of a year is considered in the SBS investment (cf. Eq. (2)).

$$
\operatorname{CLTred}^{S B S}=0.3 \cdot \sum_{t \in T}\left(\frac{t s d}{8,760} \boldsymbol{E}_{t}^{S B S}\right)
$$

The cycling lifetime is restricted by the maximum possible equivalent full cycles (CycLT ${ }^{S B S}$ ), which is simplified by the total energy throughput. This total energy throughput (left hand side of Eq. (12)) is the sum of the charging power $\left(\boldsymbol{P}_{\boldsymbol{t}}^{\boldsymbol{S B S}, \boldsymbol{c h} \boldsymbol{g}}\right.$ ) of all time slices, multiplied with the charging efficiency $\left(\eta^{S B S}\right)$, the time slice duration $(t s d)$ to receive the energy value and the battery lifetime $\left(C L T^{S B S}\right)$. This energy cannot exceed the equivalent full cycles $\left(C y c L T^{S B S}\right)$ multiplied by the battery capacity $\left(C A P^{S B S}\right)$ (right hand side of Eq. (12)).

$\sum_{t \in T}\left(\boldsymbol{P}_{\boldsymbol{t}}^{\boldsymbol{S B S}, \boldsymbol{c h g}}\right) \eta^{S B S} \cdot t s d \cdot C L T^{S B S} \leq C y c L T^{S B S} \cdot \boldsymbol{C A P} \boldsymbol{P}^{S B \boldsymbol{S}}$

As most Li-ion batteries charge according to constant current constant voltage, the charging power is reduced for high SoC (Kaschub et al., 2013). We consider a linearized charging power reduction $\left(\boldsymbol{P}_{\boldsymbol{t}}^{\boldsymbol{S B S} \text {,max,red }}\right.$ ) from maximum possible charging power $\left(\boldsymbol{P}_{\boldsymbol{t}}^{\boldsymbol{S B S}, \boldsymbol{m a x}}\right)$ for SoC above $75 \%$ (cf. Eq (13) and (14)). Right hand side Eq. (13) represents a linear relationship of the reduced charging power $\left(\boldsymbol{P}_{\boldsymbol{t}}^{\boldsymbol{S B S} \text {, } \boldsymbol{m a x}, \boldsymbol{r e d}}\right)$ according to the charged energy $\left(\boldsymbol{E}_{\boldsymbol{t}}^{\boldsymbol{S B S}}\right)$, the battery capacity $\left(\boldsymbol{C A P} \boldsymbol{P}^{\boldsymbol{S} \boldsymbol{B} \boldsymbol{S}}\right)$ and the C-Rate.

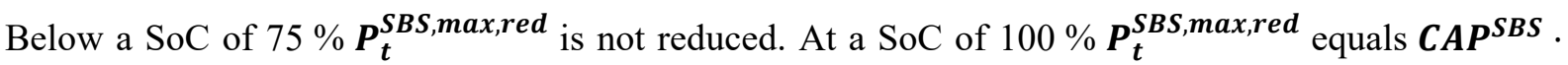
Crate. The maximum charging power $\left(\boldsymbol{P}_{\boldsymbol{t}}^{\boldsymbol{S B S}, \boldsymbol{m a x}}\right.$, left hand side of Eq. (14)) is in general limited by battery capacity and C-rate $($ Crate $\leq 1)$ and with high $\mathrm{SoC}$ values reduced by $\boldsymbol{P}_{\boldsymbol{t}}^{\boldsymbol{S B S} \text {, max,red }}$. The charging power cannot exceed a certain limit $\left(\boldsymbol{P}_{\boldsymbol{t}}^{\boldsymbol{S B S}, \boldsymbol{c h} \boldsymbol{g}} \leq \boldsymbol{P}_{\boldsymbol{t}}^{\boldsymbol{S B S}, \boldsymbol{m a x}}\right)$ and the SoC is limited to $100 \%$ $\left(E_{t}^{S B S} \leq C A P^{S B S}\right)$. 


$$
\begin{aligned}
& \boldsymbol{P}_{t}^{S B S, \text { max,red }} \geq \text { Crate }\left(4 \cdot \boldsymbol{E}_{t}^{S B S}-3 \cdot \boldsymbol{C A} \boldsymbol{P}^{S B S}\right) \\
& \boldsymbol{P}_{t}^{S B S, \text { max }}=C A P^{S B S} \cdot \text { Crate }-\boldsymbol{P}_{t}^{S B S, \text { max }, \text { red }}
\end{aligned}
$$$$
\forall t \in T
$$$$
\forall t \in T
$$

Similar to the PV inverter, also the SBS inverter has a low efficiency at low charging or discharging power. Therefore, a minimum charging power $(M C)$ is set (Hahn et al., 2013). The binary value $\left(\boldsymbol{b}_{\boldsymbol{t}}^{\boldsymbol{S B S}, \boldsymbol{c h g}}\right)$ indicates the charging process and requires zero offset (cf. Eqs. (15) and (16)).

$$
\begin{aligned}
& P_{t}^{S B S, \text { chg }}=P_{t}^{S B S, \text { chg0 }}+b_{t}^{S B S, \text { chg }} \cdot M C \\
& b_{t}^{S B S, \text { chg }} \geq \frac{P_{t}^{S B S, \text { chg } 0}}{100,000}
\end{aligned}
$$$$
\forall t \in T
$$$$
\forall t \in T
$$

The discharging minimum limit is considered correspondingly.

\subsubsection{Electric vehicles and integration modes}

Mobility patterns of the household are modeled based on empiric survey data for conventional vehicles (German Mobility Panel, MoP) (BMVBS, 2010). It includes multi-modal mobility data of households for several weeks which are assumed to be typical of the whole year for our analysis. Special trips (e. g. holidays) are not included and are assumed to be made by another mode (e. g. rental car, train, airplane). We assume the same mobility behavior for EV and a single charging facility for each household at home. Based on the survey data, we include four vehicle classes (small, medium, large; and average, if the car size is not given) and both purely battery electric vehicles (BEV) and plug-in hybrid vehicles (PHEV) with battery sizes that allow for a range of about $120 \mathrm{~km}$ for BEV (23.5; 27.5; 32.0, and $28.2 \mathrm{kWh}$ ) and $45 \mathrm{~km}$ for PHEV $(8.8 ; 10.2 ; 12.0$ and $10.6 \mathrm{kWh})$. The consumption of the vehicle classes is proportional to conventional consumption; the conversion factor is derived from Helms et al. (2010). We consider three different charging strategies in each scenario:

1. Uncontrolled charging (EVstrt): Charging starts immediately after arriving at home, with maximum possible charging power (i. e. $3.5 \mathrm{~kW}$ ).

2. Controlled charging (EVopt): Charging is controlled by the energy management system of the household by load and time and respects the limitations given by the mobility patterns.

3. Controlled bidirectional charging $(E V 2 H)$ : Similar to the controlled charging strategy, but with an additional option of discharging electricity from the EV to the household.

For controlled charging, upper and lower bounds for the SoC over time are given by input values for each time step. The bounds are determined by two extreme behaviors, instant complete charging for the upper bound $\left(S_{o} C_{t}^{E V, \max } \geq \boldsymbol{S o} \boldsymbol{C}_{\boldsymbol{t}}^{E V}\right.$ ) and latest possible charging for the next trip only for the lower bound $\left(\operatorname{SoC}_{t}^{E V, \min } \leq \boldsymbol{S o} \boldsymbol{C}_{\boldsymbol{t}}^{E V}\right)$. Between those, the load shifting potential can be used for controlled charging and discharging processes (Kaschub et al., 2013).

The SoC of the EV battery (Soc $\left.\boldsymbol{C}_{\boldsymbol{t}}^{\boldsymbol{V}}\right)$ is balanced by using the previous state of charge $\left(\boldsymbol{S o} \boldsymbol{C}_{\boldsymbol{t}-1}^{\boldsymbol{E V}}\right)$ and considering all (dis-)charging processes of the current time slice (cf. Eq. (17)). The charging $\left(\boldsymbol{S o C}_{\boldsymbol{t}}^{\boldsymbol{E V}, \boldsymbol{c h g}}\right)$ has an efficiency $\left(\eta^{E V}\right)$ of $90 \%$, the same efficiency is reached by discharging to home $\left(\boldsymbol{P}_{\boldsymbol{t}}^{\boldsymbol{E V}, \boldsymbol{d i s g}}\right)$. The mobility behavior (driving times and distances) are given exogenously. This impact on the SoC during driving is represented by $S o C_{t}^{E V, d r v}$, which reduces the $\mathrm{SoC}$ by multiplying the electricity consumption per unit $(0.235 \mathrm{kWh} / \mathrm{km}$, for average $\mathrm{EV})$ by the given mileage. 
$\operatorname{SoC}_{t}^{E V}=\operatorname{SoC}_{t-1}^{E V}+\operatorname{SoC}_{t}^{E V, c h g} \cdot \eta^{E V}-\frac{P_{t}^{E V, d i s g} \cdot t s d}{C a p^{E V} \cdot \eta^{E V}}-S_{t} C_{t}^{E V, d r v}$

$\forall t \in T$

Charging is only possible during parking times at home. In all other times the available charging power of the supply equipment $\left(P^{E V S E}\right)$ is zero. The charging infrastructure available at home together with the applied charging mode limits the maximum charging power - in our case, mode 3 charging at $3.5 \mathrm{~kW}$ (ISO 61851). As most Li-ion batteries charge according to "constant current constant voltage", the charging power is reduced for high SoC; a similar charging process is modeled for SBS. We consider a linearized charging power reduction $\left(\boldsymbol{P}_{\boldsymbol{t}}^{\boldsymbol{E V}, \boldsymbol{m a x}, \boldsymbol{r e d}}\right)$ from possible charging power of the supply equipment ( $P^{E V S E}$ ) for SoC above $75 \%$ (cf. Eq. (18)).

$\boldsymbol{P}_{\boldsymbol{t}}^{E V, \text { max }, \text { red }} \geq P^{E V S E}\left(4 \cdot \boldsymbol{S o C}_{\boldsymbol{t}}^{E V}-3\right)$

Similar to the other inverters, also the charging inverter has a low efficiency at low charging or discharging power. In line with Eqs. (15) and (16), both minimum limits for the charging of the EV and the discharging to the household are considered in our model.

Simplifying the model to linear programming by neglecting the minimum values for the inverters drastically reduces computing times (cf. Table 6). Therefore, we use the linear programming for the following reference scenario.

\subsection{Development of scenarios}

The model introduced is designed for one household with possibilities to evaluate different household technology settings. As the patterns of the household's load curves and mobility behavior are highly diverse, we use 79 empiric load curves and 80 different mobility profiles of BMVBS (2010). By applying random sampling, we analyze 225 combinations of these household load curves and mobility profiles.

We use a reference scenario $(R E F)$ with the values introduced in the sections above. It includes four variants (cf. Figure 2) to consider EV integration with different charging strategies ( $R E F \_n o E V$, $R E F_{-} E V s t r t, R E F_{-} E V o p t$ and $\left.R E F_{-} E V 2 H\right)$. For the variant $R E F_{-} n o E V$ we use the sample size of the 79 empiric load curves and for the other three variants with EV, we use 225 combinations of household load curves and mobility profiles. Three model runs enable the NPV evaluation of the PV system and SBS independently, as explained in section 3.2.

The possibility of influencing the load of customers (i. e. demand side management or demand response measures) is based on their willingness to participate in these measures and their technically available load shifting potentials (Dütschke and Paetz, 2013; Kaschub et al., 2013). Controlled charging of both EV and SBS increases this potential considerably. We therefore analyze several scenarios as to how different electricity tariffs (pricing schemes) might influence the load.

Today, the normal electricity tariff in Germany includes a small basic charge (fixed part, in EUR/month) and an energy charge (variable part or electricity price). This electricity price was $29.5 \mathrm{ct} / \mathrm{kWh}$ on the average for 2014 (BNetzA, 2014) with the following shares: About $27 \%$ for electricity generation and sales, $22 \%$ for network use of system charges (UoSC), $7 \%$ electricity tax, $16 \%$ value added tax, $5 \%$ concession fees, and the remaining $23 \%$ are surcharges for EEG, CHP, and others (BNetzA, 2014). 
First, we look at the UoSC electricity price component $(6.5 \mathrm{ct} / \mathrm{kWh})$, which pays the grid operators (transmission and distribution grid) for providing the grid. This price component has already been discussed for some years (Giessing, 2010; Illing et al., 2011; Sakhrami and Parsons, 2010). Further decentralization, rising feed-in in the distribution grids, and increasing self-consumption counteract the fair distribution of UoSC and the current principle of cost roll-overs by grid level. Therefore, we consider several alternative scenarios as how the UoSC might be included in the electricity tariff in the future. The results are given in section 4.3.

FIX The UoSC are included in the fixed part (basic charge) of the electricity tariff with about 205 EUR/year. This can be understood as charge for the household's power connection independently of the exchanged amounts of electricity.

PEAK UoSC are considered a demand charge of the electricity tariff by charging the maximum peak load during one year with $18 \mathrm{EUR} / \mathrm{kW}$. This would be a new tariff component for German household customers, whereas such a demand charge is already used for industrial customers.

$F \& P \quad$ A combined scenario of $F I X$ and PEAK with UoSC divided into 100 EUR/year for connection and $20 \mathrm{EUR} / \mathrm{kW}$ for the annual peak load.

Second, we look at alternative possibilities to incentivize load shifting either to reduce load peaks (reduce stress in distribution networks) or to improve integration of renewable energy sources.

According to German regulation introduced in the 2012 amendment of EEG, the feed-in is limited to $70 \%$ of $\boldsymbol{P}^{P V \text {,peak }}$ (“curtailment") for small PV systems $\left(<30 \mathrm{~kW}_{\mathrm{p}}\right)$, which do not participate in the feedin management of the grid system operator (EEG, 2014). Another possibility to incentivize load shifting is based on dynamic pricing. To reduce peaks, load or feed-in limits can be used. Timevarying electricity prices are a more common option, which have already been applied in Germany for a long time in special time of use (ToU) contracts. We therefore evaluate another three scenarios; the results are also given in section 4.3.

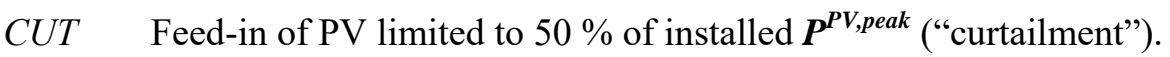

LIMIT Load limit at $4 \mathrm{~kW}$ and feed-in limit of $2 \mathrm{~kW}$. Beyond these limits, loads or feed-in are penalized with $10 \mathrm{ct} / \mathrm{kWh}$ (dynamic pricing by load).

ToU Time of use tariff (dynamic pricing by time) with two time blocks per day and an increased price by $10 \%\left(p f_{t}=1.1\right)$ in the daytime from 8 a.m. to 8 p.m. (otherwise, $p f_{t}=0.9$ ).

\section{Results}

We now evaluate the reference scenario and following scenarios with the developed model. Figure 2 gives an overview about the scenarios including structure of this chapter. Further aspects are given in section 4.4. The optimal sizing of the system components (i. e. PV and SBS) and the corresponding NPV are the main results. For better readability of the results, we in general present average values and complement them in the result tables by the standard deviation (SD) in brackets in order to highlight the diversity of results for the evaluated households. 


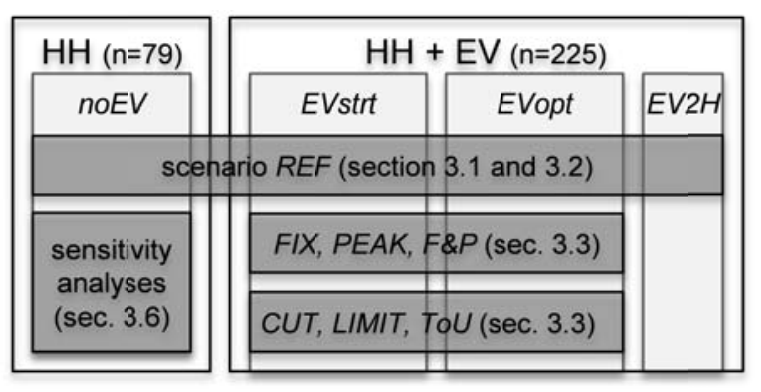

Figure 2: Scenario overview with variants of EV integration

\subsection{Photovoltaic system and stationary battery system without EV}

As explained in section 3.2, we use three system setups for calculating the NPV. We first evaluate the implications of a PV system of our reference scenario without EV (REF_noEV) with the system setup including PV, but no SBS. For all given households ( $\mathrm{n}=79)$, a PV system is profitable under the given assumptions (cf. sections 3.2 and 3.3). On the average, the model estimates an optimal peak power for the PV system $\boldsymbol{P}^{\boldsymbol{P V} \text {,peak }}$ of $1.7 \mathrm{~kW}_{\mathrm{p}}$ and an optimal $\boldsymbol{N} \boldsymbol{P} \boldsymbol{V}^{\boldsymbol{P V}}$ of $1,978 \mathrm{EUR}$, which exhibits a high variance between the households (cf. Figure 3). The average self-consumption rate of $55.1 \%$ is relatively high, because the PV system is rather small-dimensioned. Consequently, the self-coverage ${ }^{3}$ rate of $21.9 \%$ is low.

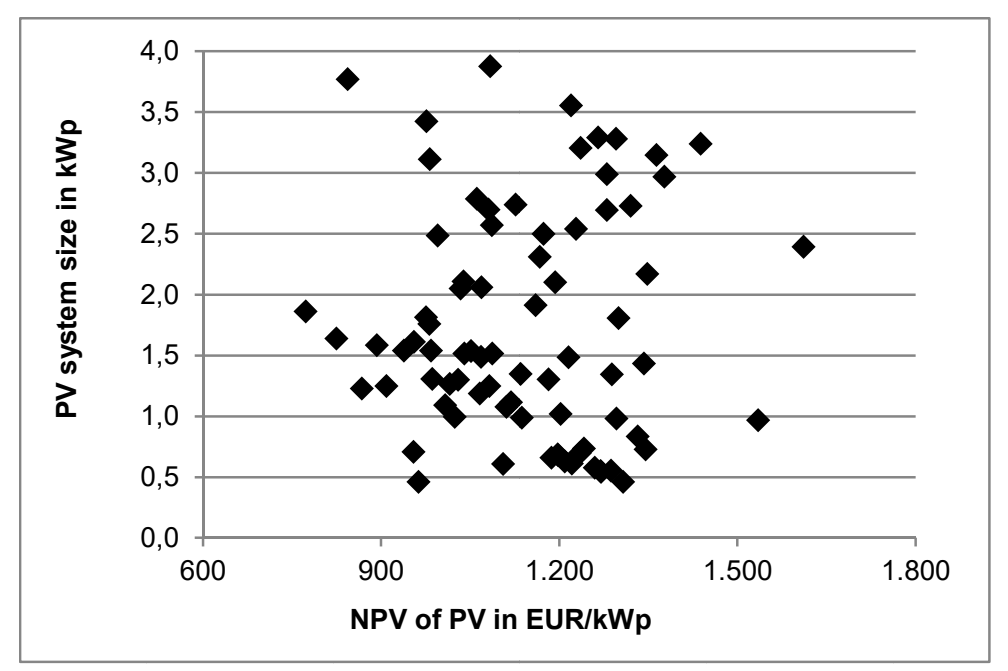

Figure 3: Scatter plot of PV system size vs. NPV (REF_noEV)

Secondly, when including the SBS besides a PV system, the results show that the installation of SBS is profitable for all households under the assumption of optimal system sizes and use of the SBS. The SBS system size is optimal with a relatively low capacity, but the size of the PV system increases by about $60 \%$ compared to the system setup without SBS (cf. Table 1). Consequently, the selfconsumption (about $68 \%$ ) and self-coverage rate (about $43 \%$ ) are significantly higher.

\footnotetext{
${ }^{3}$ The self-coverage rate is the PV electricity production, which is self-consumed, divided by the overall household electricity consumption.
} 
Table 1: Characteristic average values $\left(\mathrm{CAP}^{\mathrm{SBS}}, \mathrm{NPV}^{\mathrm{SBS}}, \mathrm{P}^{\mathrm{PV}, \text { peak }}\right.$, self-consumption, selfcoverage) for households with PV or PV \& SBS but without EV (REF_noEV, n=79)

\begin{tabular}{|l|c|c|c|c|c|}
\hline & $\begin{array}{c}\boldsymbol{C A} \boldsymbol{P}^{\boldsymbol{S} \boldsymbol{S}} \\
\text { in } \mathrm{kWh}\end{array}$ & $\begin{array}{c}\boldsymbol{N} \boldsymbol{P} \boldsymbol{V}^{\boldsymbol{S B S}} \\
\text { in EUR }\end{array}$ & $\begin{array}{c}\boldsymbol{P}^{\boldsymbol{P V} \text {, } \boldsymbol{p e a k}} \\
\text { in } \mathrm{kW}_{\mathrm{p}}\end{array}$ & $\begin{array}{c}\text { self- } \\
\text { consumption } \\
\text { rate (SD) in \% }\end{array}$ & $\begin{array}{c}\text { self-coverage } \\
\text { rate (SD) } \\
\text { in \% }\end{array}$ \\
\hline PV & -- & -- & $1.7(0.9)$ & $55.1(4.3)$ & $21.9(5.4)$ \\
\hline PV \& SBS & $2.0(0.9)$ & $624(353)$ & $2.7(1.2)$ & $67.9(2.9)$ & $43.1(7.1)$ \\
\hline
\end{tabular}

Not unexpected, the inclusion of SBS has an impact on the household's pattern of grid electricity demand (cf. Figure 4). During sunny daytimes, we see high PV feed-in or negative loads. With SBS this effect is even higher (due to a larger PV system). In our REF scenario, peaks for the grid are not reduced, as there is no incentive yet.

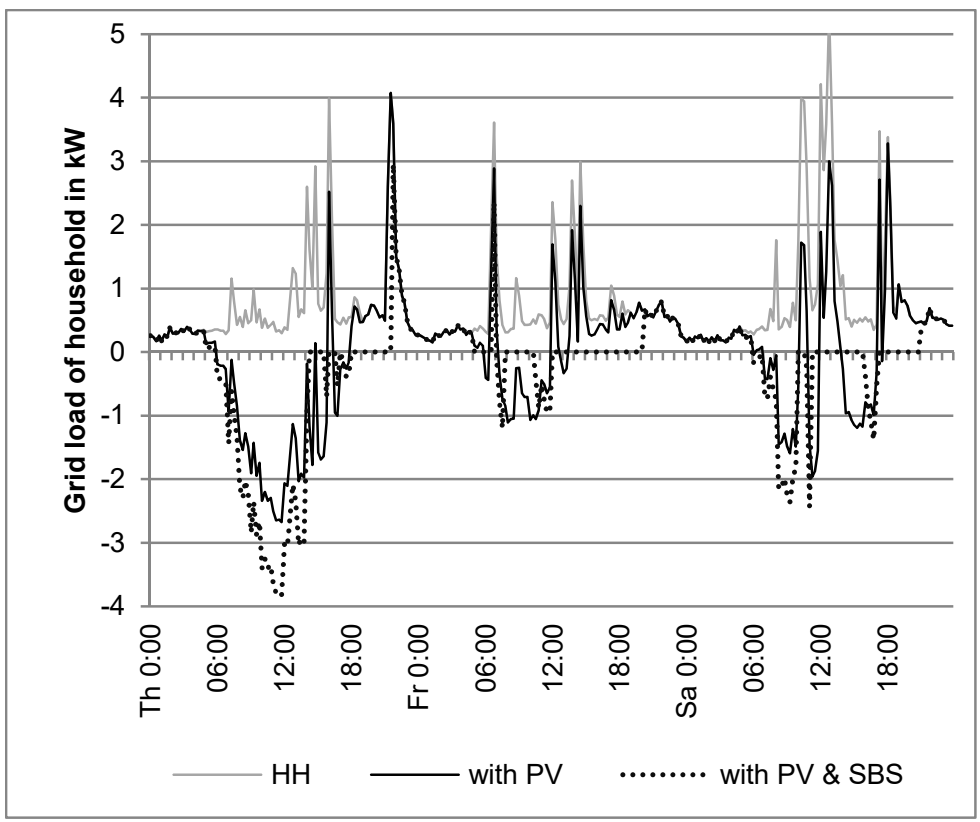

Figure 4: Example of grid load of household (REF_noEV, in spring)

The usual cycle period of the SBS is one day. If possible, the SBS is charged by PV in the afternoon and discharged in the early evening. Charging in the early morning is only used, if PV electricity is not affluent because of higher calendar aging during high SoC. Partial charging with several (partial) cycles is observed during cloudy days only.

A complete autarkic household without connection to the power grid and no emissions is not

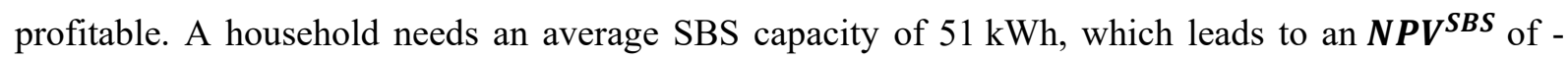
66,101 EUR. Results are similar for autarkic households with EV (EVopt).

\subsection{Electric vehicle integration}

When adding an EV to the considered system, we observe a high impact on dimensioning and profitability. Based on the higher electricity consumption, both the PV system and SBS are dimensioned larger (cf. Table 2). The more the EV is integrated into the home (i. e. from instant charging via optimized charging to EV2H), the larger is the PV system and the slightly higher is the self-consumption rate. Consequently, the total $\boldsymbol{N P V} \boldsymbol{V}^{\boldsymbol{P V}+\boldsymbol{S B S}}$ is increased, too. Simultaneously, the 
optimal SBS capacity and NPV of the SBS are reduced. For $9 \%$ of the households, SBS become unattractive (negative NPV), as EV2H replaces some part of SBS electricity turnover.

Table 2: Characteristic average values (and SD) of CAP ${ }^{\mathrm{SBS}}, \mathrm{P}^{\mathrm{PV} \text {,peak }}$, NPV, self-consumption for all households with EV, PV, and SBS (REF, $n=225)$

\begin{tabular}{|c|c|c|c|c|c|c|c|}
\hline \multirow{2}{*}{$\begin{array}{l}\mathrm{EV} \\
\text { integration of } \\
R E F\end{array}$} & \multicolumn{2}{|c|}{ profitability $^{a}$} & \multirow{2}{*}{$\begin{array}{c}P^{P V, \text { peak }} \\
(\mathrm{SD}) \\
\text { in } \mathrm{kW}_{\mathrm{p}}\end{array}$} & \multirow{2}{*}{$\begin{array}{c}\boldsymbol{C A} \boldsymbol{P}^{\boldsymbol{S B S}} \\
(\mathrm{SD}) \\
\text { in } \mathrm{kWh}\end{array}$} & \multirow{2}{*}{$\begin{array}{c}\boldsymbol{N P V ^ { S B S }} \\
(\mathrm{SD}) \\
\text { in EUR }\end{array}$} & \multirow{2}{*}{$\begin{array}{c}\boldsymbol{N} \boldsymbol{P} \boldsymbol{V}^{P V+S B S} \\
(\mathrm{SD}) \\
\text { in EUR }\end{array}$} & \multirow{2}{*}{$\begin{array}{c}\text { self- } \\
\text { consumption } \\
\text { rate in \% }\end{array}$} \\
\hline & PV & SBS & & & & & \\
\hline REF_EVstrt & $100 \%$ & $100 \%$ & $3.8(1.7)$ & $3.0(1.5)$ & $1,954(994)$ & $3,438(1,904)$ & $67.4(3.0)$ \\
\hline REF_EVopt & $100 \%$ & $100 \%$ & $4.6(2.0)$ & $2.8(1.6)$ & $1,802(1,037)$ & $5,272(2,136)$ & $69.5(4.7)$ \\
\hline$R E F \_E V 2 H$ & $100 \%$ & $91 \%$ & $5.3(1.8)$ & $1.8(1.9)$ & $796(1,176)$ & $6,459(2,994)$ & $71.3(6.9)$ \\
\hline
\end{tabular}

${ }^{\text {a }}$ Share of households, where technology (PV or SBS) is profitable.

Concerning the electricity exchange with the grid, there are several effects. As expected, the EV increases electricity demand of household (without PV-SBS) in average to about $140 \%$, whereas PV and SBS decrease the household demand from grid (without EV) to $78 \%$ or $58 \%$ in average (cf. Table 3) as self-consumption covers the remainder part of electricity consumption. The average peak loads, however, are not significantly affected by these three technologies. Peak feed-in is increased by the PV system, SBS, and EV.

Table 3: Characteristic average values (and SD) of electricity demand, peak load and feed-in for grid usage $(R E F, n=225)$

\begin{tabular}{|l|c|c|c|c|c|c|}
\hline \multirow{2}{*}{} & \multicolumn{2}{|c|}{$\begin{array}{c}\text { electricity demand } \\
\text { in } \mathrm{kWh} / \mathrm{year}\end{array}$} & \multicolumn{2}{c|}{$\begin{array}{c}\text { peak load } \\
\text { in } \mathrm{kW}_{\mathrm{p}}\end{array}$} & \multicolumn{2}{c|}{$\begin{array}{c}\text { peak feed-in } \\
\text { in } \mathrm{kW}_{\mathrm{p}}\end{array}$} \\
\cline { 2 - 7 } & noEV & EVopt & noEV & EVopt & noEV & EVopt \\
\hline HH only & 3,812 & 5,383 & 11.8 & 11.9 & 0 & 0 \\
\hline HH with PV & 2,956 & 3,478 & 11.6 & 11.3 & -1.4 & -2.9 \\
\hline HH with PV and SBS & 2,234 & 2,605 & 11.5 & 10.9 & -2.2 & -3.7 \\
\hline
\end{tabular}

Figure 5 illustrates electricity demand from the grid over time. The presence of an EV roughly doubles demand in the evening hours. The generation of PV electricity has a dominating influence. During sunny daytime, the grid load is negligible, but feed-in outperforms peak loads. The presence of SBS further increases these effects. 


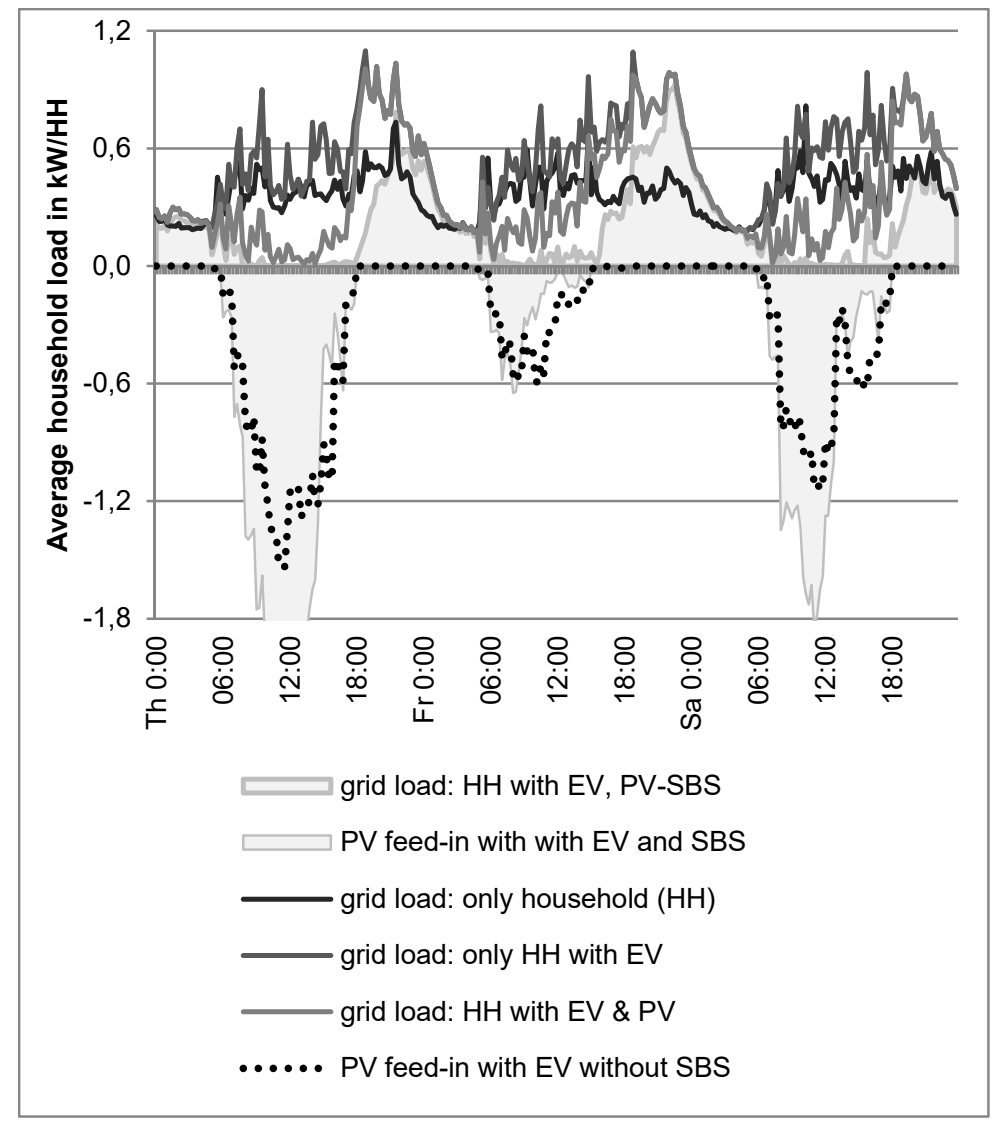

Figure 5: Average grid load and feed-in for all households $\left(R E F \_E V s t r t\right.$, in spring, $\left.n=225\right)$

\subsection{Impact of tariff scenarios}

The flexibility for load management is given by SBS and controlled charging of EV. We evaluate the results for uncontrolled (EVstrt) and controlled charging (EVopt) in order to additionally compare this relevant aspect. As explained in section 3.4, we first examine three electricity tariff scenarios of integrating the UoSC in a way that differs from the current German solution. In scenario FIX the comparative advantage of self-consumption is reduced. As a result, this electricity tariff would lead to a negative impact on the installation of PV systems and SBS compared to REF (cf. Table 4). In scenario PEAK the SBS has the ability to reduce peak load to nearly one third of REF and the endogenously optimized capacity and NPV are similar compared to REF (cf. Table 4). The combined tariff in scenario $F \& P$ results in effects similar to those of a solely peak load-based UoSC. The fixed part obviously has a minor influence. The effects of EVstrt and EVopt are similar.

The second part of the scenarios includes more possibilities to influence the household load and feedin curves. The scenario CUT with $50 \%$ curtailment of PV feed-in only has a low impact on the profitability and dimensioning of the PV system and SBS compared to REF (cf. Table 5). The average feed-in peak is reduced from $3.1 \mathrm{~kW}$ to $2.2 \mathrm{~kW}$ in the CUT_EVstrt scenario and from $3.7 \mathrm{~kW}$ to $2.8 \mathrm{~kW}$ in the CUT_EVopt scenario. In our LIMIT scenario with a dynamic pricing scheme relating to load, we see a reduction of peak loads and also of feed-in. This scenario has a low negative impact on profitability and dimensioning of the PV system and SBS compared to REF. In the LIMIT_EVstrt scenario the average feed-in peak is reduced to $2.2 \mathrm{~kW}$ and the peak load from $12.7 \mathrm{~kW}$ to $8.1 \mathrm{~kW}$. For the LIMIT_EVopt scenario the feed-in peak is reduced to $2.6 \mathrm{~kW}$ and the peak load from $10.9 \mathrm{~kW}$ to $7.3 \mathrm{~kW}$. The dynamic pricing scheme with time-varying electricity prices (scenario $T o U$ ) also has a small positive influence on the profitability and dimensioning of the PV system and SBS compared to 
$R E F$. In the ToU_EVstrt scenario the demand share in low price times increases from $63 \%$ to $72 \%$. In the ToU_EVopt scenario it increases from $64 \%$ to $80 \%$.

Table 4: Results for power demand, peak load, $\mathrm{CAP}^{\mathrm{SBS}}, \mathrm{P}^{\mathrm{PV} \text {,peak }}$, NPV of different scenarios for UoSC based on average values (and SD) $(n=225)$

\begin{tabular}{|c|c|c|c|c|c|c|}
\hline $\begin{array}{l}\text { scenario for } \\
\text { UoSC }\end{array}$ & $\begin{array}{c}\text { power demand } \\
(\mathrm{SD}) \\
\text { in } \mathrm{kWh} / \text { year }\end{array}$ & $\begin{array}{l}\text { peak load } \\
\text { (SD) } \\
\text { in } \mathrm{kW}_{\mathrm{p}}\end{array}$ & $\begin{array}{c}\boldsymbol{P}^{P V}, \text { peak } \\
\text { for } \mathrm{HH}+\mathrm{PV} \\
\quad(\mathrm{SD}) \\
\text { in } \mathrm{kW}_{\mathrm{p}}\end{array}$ & $\begin{array}{c}\boldsymbol{N} \boldsymbol{P V ^ { P V }} \\
(\mathrm{SD}) \\
\text { in EUR }\end{array}$ & $\begin{array}{c}\boldsymbol{C} \boldsymbol{A} \boldsymbol{P}^{\boldsymbol{S B S}}(\mathrm{SD}) \\
\text { in } \mathrm{kWh}\end{array}$ & $\begin{array}{c}\boldsymbol{N P V ^ { S B S }}(\mathrm{SD}) \\
\text { in } \mathrm{EUR} / \mathrm{kWh}\end{array}$ \\
\hline$R E F \_E V s t r t$ & $3,210(1,173)$ & $12.7(7.2)$ & $2.4(1.6)$ & $3,288(2,173)$ & $3.0(1.5)$ & 1,954 (994) \\
\hline$F I X \_E V s t r t$ & $3,853(1,559)$ & $12.9(7.2)$ & $1.8(1.3)$ & $2,487(1,713)$ & $1.4(0.8)$ & $878(531)$ \\
\hline PEAK_EVstrt & $3,400(1,535)$ & $4.9(2.6)$ & $1.9(1.3)$ & $2,540(1,726)$ & $2.9(1.5)$ & $1,938(1,023)$ \\
\hline$F \& P \_E V s t r t$ & $3,359(1,531)$ & $4.7(2.4)$ & $1.9(1.3)$ & $2,547(1,728)$ & $3.1(1.6)$ & $2,059(1,086)$ \\
\hline REF_EVopt & 2,605 (949) & $10.9(6.8)$ & $3.7(2.2)$ & $4,969(2,974)$ & $2.8(1.6)$ & $1,802(1,037)$ \\
\hline FIX_EVopt & $3,245(1,197)$ & $11.2(6.8)$ & $3.1(1.9)$ & $4,150(2,632)$ & $1.2(0.8)$ & $751(532)$ \\
\hline PEAK_EVopt & $2,812(1,243)$ & $3.6(2.8)$ & $3.1(1.9)$ & $4,196(2,633)$ & $2.8(1.5)$ & $1,848(995)$ \\
\hline F\&P_EVopt & $2,781(1,234)$ & $3.8(2.9)$ & $3.1(1.9)$ & $4,204(2,633)$ & $3.0(1.6)$ & $1,947(1,037)$ \\
\hline
\end{tabular}

Table 5: Results for power demand, peak load, $\mathrm{CAP}^{\mathrm{SBS}}, \mathrm{P}^{\mathrm{PV} \text {,peak }}$, NPV of different scenarios for load shifting based on average values (and SD) $(n=225)$

\begin{tabular}{|c|c|c|c|c|c|c|}
\hline scenario & $\begin{array}{c}\text { power demand } \\
\qquad(\mathrm{SD}) \\
\text { in } \mathrm{kWh} / \text { year }\end{array}$ & $\begin{array}{c}\text { peak load } \\
(\mathrm{SD}) \\
\text { in } \mathrm{kW}_{\mathrm{p}}\end{array}$ & $\begin{array}{c}P^{P V, p e a k} \\
\text { for } \mathrm{HH}+\mathrm{PV} \\
\quad(\mathrm{SD}) \\
\text { in } \mathrm{kW}_{\mathrm{p}}\end{array}$ & $\begin{array}{c}\boldsymbol{N} \boldsymbol{P} \boldsymbol{V}^{P \boldsymbol{V}} \\
(\mathrm{SD}) \\
\text { in EUR }\end{array}$ & $\begin{array}{c}\boldsymbol{C A P}^{\boldsymbol{S B S}} \\
(\mathrm{SD}) \\
\text { in } \mathrm{kWh}\end{array}$ & $\begin{array}{c}\boldsymbol{N P V ^ { S B S }} \\
(\mathrm{SD}) \\
\text { in EUR }\end{array}$ \\
\hline REF_EVstrt & $3,210(1,173)$ & $12.7(7.2)$ & $2.4(1.6)$ & $3,288(2,173)$ & $3.0(1.5)$ & 1,954 (994) \\
\hline CUT_EVstrt & $3,216(1,283)$ & $12.7(7.2)$ & $2.3(1.6)$ & $3,193(2,121)$ & $3.0(1.5)$ & 1,961 (999) \\
\hline LIMIT_EVstrt & $3,271(1,375)$ & $8.1(5.8)$ & $2.3(1.2)$ & $3,058(1,691)$ & $2.9(1.3)$ & $1,946(893)$ \\
\hline ToU_EVstrt & $3,132(1,248)$ & $12.9(7.2)$ & $2.7(1.7)$ & $3,667(2,366)$ & $3.3(1.6)$ & $2,194(1,078)$ \\
\hline REF_EVopt & 2,605 (949) & $10.9(6.8)$ & $3.7(2.2)$ & $4,969(2,974)$ & $2.8(1.6)$ & $1,802(1,037)$ \\
\hline CUT_EVopt & $2,608(951)$ & $10.9(6.7)$ & $3.6(2.2)$ & $4,900(2,932)$ & $2.8(1.6)$ & $1,809(1,054)$ \\
\hline LIMIT_EVopt & $2,692(1,120)$ & $7.3(5.6)$ & $3.3(1.7)$ & $4,552(2,343)$ & $2.8(1.5)$ & $1,862(1,009)$ \\
\hline ToU_EVopt & $2,699(1,015)$ & $11.4(6.5)$ & $3.6(2.1)$ & $4,929(2,800)$ & $2.6(1.2)$ & $1,726(822)$ \\
\hline
\end{tabular}




\subsection{Impact on carbon dioxide emissions}

The average specific carbon dioxide emissions associated with German electricity amounted to about $0.57 \mathrm{~kg} / \mathrm{kWh}$ il 2014 - however, with a decreasing tendency (UBA, 2015). Jochem et al. (2015) analyzed the hourly $\mathrm{CO}_{2}$ emissions per unit in the grid for 2030 and found an average $\mathrm{CO}_{2}$ emission factor of $0.29 \mathrm{~kg} / \mathrm{kWh}_{\mathrm{el}}$. According to our results, the renewable self-coverage of a household (REF_EVopt) can amount to about $50 \%$ by PV. For 2030, this means a nominal emission factor for the household's electricity consumption of about $0.15 \mathrm{~kg} / \mathrm{kWh}$ el or $34 \mathrm{~g} / \mathrm{km}$ for EV when charging solely at home $(0.235 \mathrm{kWh} / \mathrm{km})$. Compared to 1990 , the emission factor per unit is reduced by about $75 \%$. This personal emission factor of $34 \mathrm{gr} \mathrm{CO}_{2}$ per $\mathrm{km}$ for $\mathrm{EV}$ is far below the target value for newly registered passenger vehicles in the European Union in 2030, which is about $70 \mathrm{gr} \mathrm{CO}_{2} / \mathrm{km}$ (Thiel et al., 2014)

\subsection{Model complexity}

Although applied inverters have a minimum load level, most studies have not considered them so far (Babrowski et al., 2014; Dufo-Lopez and Bernal-Augustin, 2015; Erdinc, 2014; Zucker and Hinchliffe, 2014). When considering the inverter's start-up gap, it is necessary to introduce a binary variable $\boldsymbol{b}_{\boldsymbol{t}}^{\boldsymbol{E V}, \boldsymbol{c h} \boldsymbol{g}}$ (cf. Eqs. (15) and (16)) in the model. As a result, linear programming (LP) becomes a mixed integer programming (MIP) problem and computation times increase drastically. The impact on the results (i. e. the installed capacity of the SBS and the NPV of the SBS), however, is marginal (cf. Table 6). We therefore support the current practice to omit this technical consideration for energy system models here. The result and consequence are similar for the technical fact of charging power being reduced smoothly at the end of the charging process of Li-ion batteries (Kaschub et al., 2013) (cf. Eq. (18)). Even though this has an impact on the overall charging time, the influence on the results

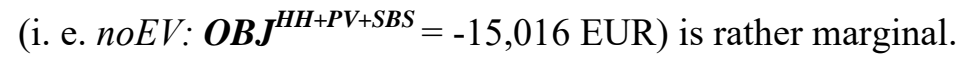

Table 6: Comparison of LP to MIP calculation with inverter start-up gap (average values, $n=79$ )

\begin{tabular}{|c|c|c|c|c|c|c|}
\hline & & $\begin{array}{c}\boldsymbol{O} \boldsymbol{B J}^{\boldsymbol{S B S}} \\
(\mathrm{SD}) \\
\text { in EUR }\end{array}$ & $\begin{array}{l}\text { MIP } \\
\text { relative } \\
\text { gap in } \\
\%\end{array}$ & $\begin{array}{l}\text { solving } \\
\text { time } \\
\text { in } \mathrm{h}\end{array}$ & $\begin{array}{c}\boldsymbol{C A} \boldsymbol{P}^{\boldsymbol{S B S}} \\
(\mathrm{SD}) \\
\text { in } \mathrm{kWh}\end{array}$ & 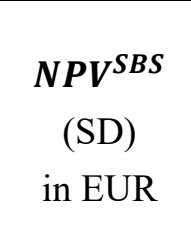 \\
\hline \multirow{2}{*}{$n o E V$} & LP & $-15,027(6,141)$ & -- & 1.7 & $2.0(0.9)$ & $624(353)$ \\
\hline & MIP & $-15,258(6,145)$ & 1.2 & 54.0 & $1.5(0.8)$ & 393 (347) \\
\hline \multirow{2}{*}{ EVopt } & LP & $-16,600(7,230)$ & -- & 3.7 & $2.1(0.8)$ & $1,371(543)$ \\
\hline & MIP & $-16,855(6,040)$ & 1.3 & 177.8 & $1.8(0.7)$ & $1,154(480)$ \\
\hline
\end{tabular}




\subsection{Sensitivity analysis for system}

The results of the model are dependent on several input parameters, most of which are associated with uncertainties - especially for the time horizon of 20 years. For this reason, we conduct sensitivity analyses for the main parameters influencing the resulting NPV. We use the reference scenario without $\mathrm{EV}\left(R E F \_n o E V\right)$ for clearer understanding.

The NPV of the PV system is highly influenced by its investment costs and the assumed interest rate (cf. Figure 6). Decreased investment costs (e. g. by a cheaper inverter) to $75 \%$ compared to our reference case results in an NPV increase to about $140 \%$ and average installed peak power rises from $1.7 \mathrm{~kW}_{\mathrm{p}}$ to $2.7 \mathrm{~kW}_{\mathrm{p}}$. The electricity price increase has an important influence on the NPV of the PV system, too. Calendar lifetime is less sensitive. A (limited) deviation from optimal PV system size only has a marginal negative effect on the NPV.

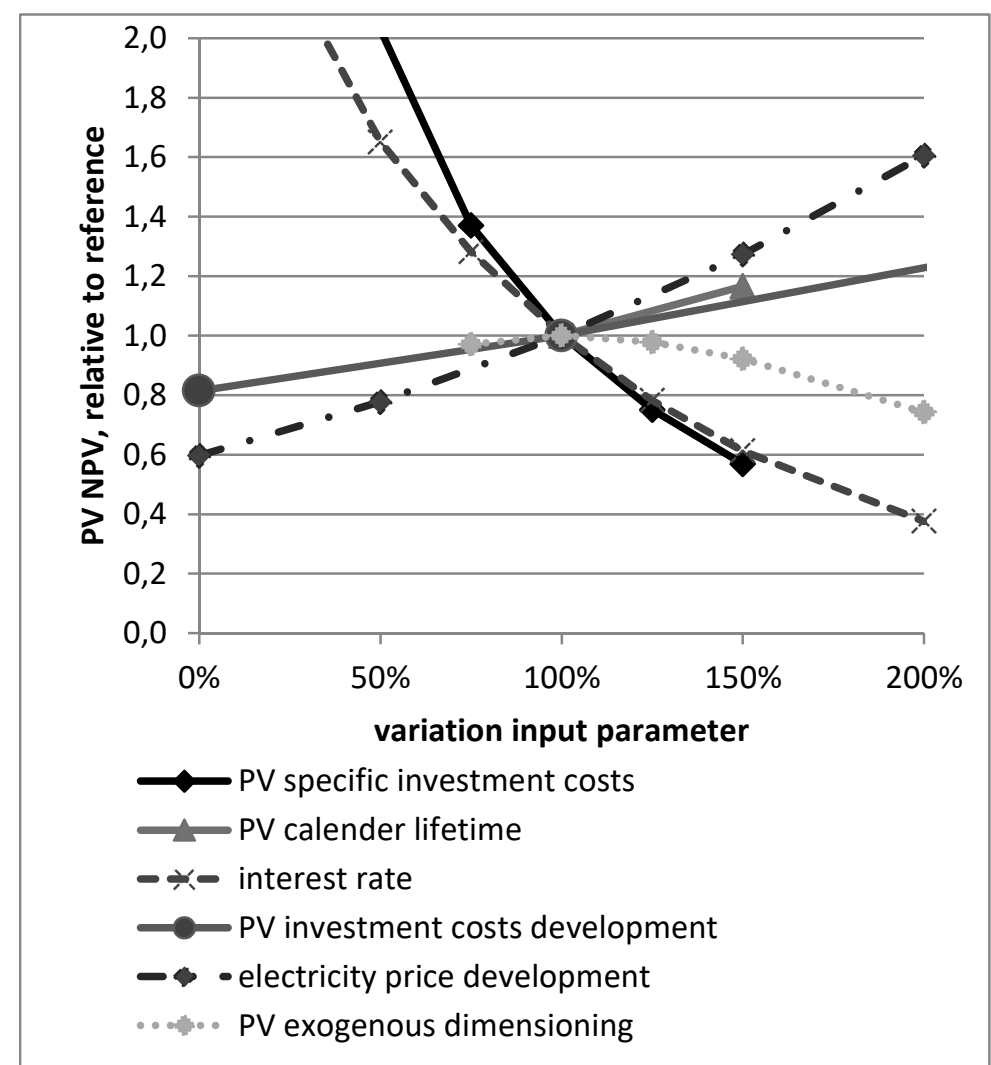

Figure 6: Sensitivity analysis for PV system NPV (REF_noEV, $n=79)$

In contrast to this, the impact on the NPV of the SBS is more significant (cf. Figure 7). The electricity price development has an even higher influence as has the considered interest rate. Furthermore, a decrease of investment costs by $50 \%$ increases SBS NPV to about $350 \%$ and the capacity to about $300 \%$. Calendar and cycle lifetime characteristics of SBS are important as well. Further influencing input parameters with less impact are c-rate, the calendar lifetime of $\mathrm{PV}$, and development of PV investment costs. 


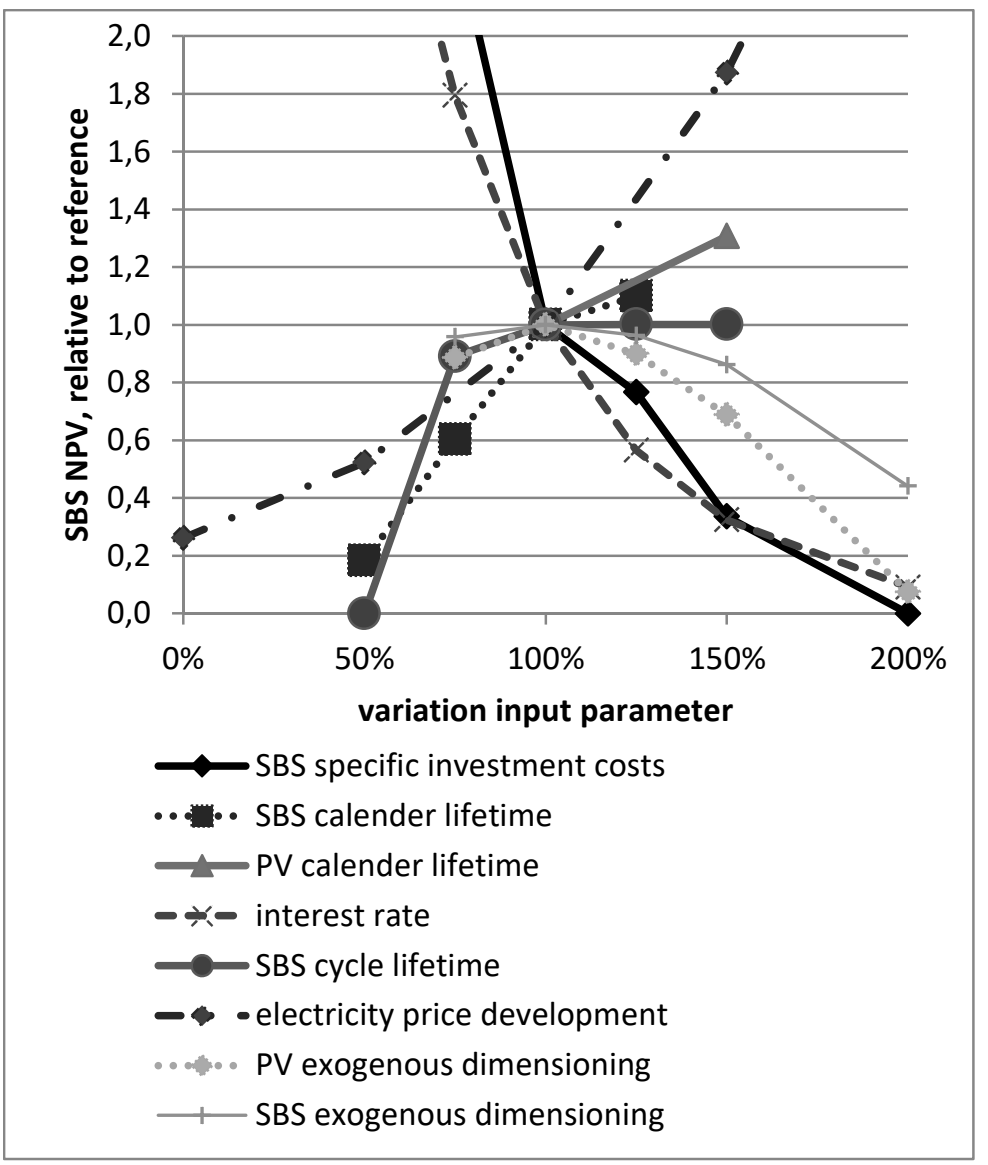

Figure 7: Sensitivity analysis for SBS NPV $\left(R E F \_n o E V, n=79\right)$

The sensitivities on the SBS are similar, if an EV is present. For REF_EVopt an investment of only 250 EUR/kWh (750 EUR/kWh) results in an NPV of $310 \%$ (30\%) compared to REF.

Changing weather input data from test reference years to purely historical data from Karlsruhe for the years 2008 to 2010 (IMK, 2014) reveals slightly higher NPV for PV of 1 to $7 \%$. The NPV for $\mathrm{PV}+\mathrm{SBS}$ is 3 to $14 \%$ higher. This indicates that the uncertainties and differences resulting from the weather are of minor importance compared to other influencing factors.

\section{Discussion}

In the following discussion we firstly discuss the results of chapter 4. Secondly, we focus the discussion on the general implications of the German electricity system.

\subsection{Discussion of model results}

The results of our modeling work of households in Southwest Germany (base year 2018) show positive NPV for PV systems without subsidies (on the average 1,978 EUR, cf. section 4.1). Main drivers are a high self-consumption rate, falling investment costs, and a further rising electricity price (cf. section 4.6). The combination of a PV system with an SBS increases the benefit to an average of 2,602 EUR. As market prices for SBS (Fuhs, 2014) are still beyond profitable application today (cf. Figure 7), the current German funding scheme for SBS in combination with PV (KfW, 2015) seems to be a good step for introducing these systems. The further falling market prices for SBS, however, will make this funding measure superfluous soon. 
In case an EV is present at a household with PV system (and SBS), controlled charging has a positive impact (cf. section 4.2): A larger PV system with a rising self-consumption to around $70 \%$ is reasonable and increases the NPV for PV-SBS to 5,272 EUR.

These results of domestic PV-SBS with EV display a significantly changing load curve, even without controlled charging (cf. Figure 5). External procurement of electricity during daytime is increasingly replaced by feed-in of PV electricity. In the evening, peak loads increase. Overall, the procurement of electricity from utilities is reduced to $48-58 \%$ on the average. Due to the increasing NPV of these systems in the future, the share of the households equipped with these systems might increase considerably. This will have a severe impact on several major aspects of local energy systems:

(1) Decreased electricity supply by utilities with an influence on the profitability of power plants,

(2) Declining electricity demand by households, but remaining (or increasing) surcharges and UoSC, and

(3) Increasing fluctuations in the local low-voltage grid with increasing return flows and higher demand peaks e. g. by EV charging.

The results obtained with different electricity tariff scenarios reveal two possibilities to master the upcoming challenges. One solution might be the restructuring of electricity tariffs e. g. by transforming the energy-dependent UoSC part of the electricity price into a demand charge or basic charge (section 4.3 and Table 4). Another alternative is to technically influence the domestic flexibilities of the storage system or EV charging. A demand charge would be a new electricity price component for German household customers and could, according to our results, reduce peak loads to less than half of the reference peak. Load limits or load-depending dynamic prices seem to be appropriate measures in this context, too. The results of our optimization model indicate a reduction of peak load by approximately one third. As regards the feed-in peaks, our results confirm the positive effect of the measure already existing in the EEG of curtailing PV. Direct feed-in limits (similar to load limits) would be another possible measure. The evaluated ToU tariff shows the effectiveness of load shifting to times with a cheap electricity price, but also the risk of additional load peaks.

\subsection{Discussion of implications for the German electricity system}

In the following we try to transfer our modeling results to German electricity system, which is one market region. Our results are not representative of Germany. However, the applied household load curves are not unusual and their sum is close (MSD with $2 \%$ ) to the German standard synthetic load profile of households, called H0 (Schieferdecker et al., 1999). The used mobility profiles are taken from a representative German mobility study.

Our results provide strong evidence that with further improving market conditions, a fast market penetration of PV-SBS systems is highly probable in the near future. When we scale our results to the national electricity demand of about 17.7 million German single- and two-family houses (Destatis 2014), the reduction of electricity procurement amounts to about $28 \mathrm{TWh}$ per year. This would be a reduction of German gross electricity consumption (597 TWh; BMWi, 2016) of $4.7 \%$ and $22 \%$ of the total German household demand (127 TWh; BMWi, 2016). Not included are apartment buildings with 21.6 million households (Destatis, 2014). Other upcoming technologies, such as EV, combined heat and power (CHP) plants or heat pumps, might accelerate the process of changing the demand structure as well. 
This gives rise to the question of whether such technology can be a game changer in the German electricity sales market. We take the three aspects from section 5.1 to discuss this question:

(1) The effects of a high share of PV systems on merit order and the electricity price have already been discussed in several studies. Tveten et al. (2013) and Cludius et al. (2014) indicated a merit order effect with a decrease of electricity prices by PV (and wind) generation in Germany. Satchwell et al. (2015) concluded for the United States that PV self-consumption leads to decreasing sales by the utility, which erodes their revenues and increases electricity prices. To sum up, the PV systems affect merit-order, revenues of utilities and the electricity price. It seems probable that SBS will intensify these effects.

(2) Looking at the household electricity price, the already mentioned decreasing demand by $22 \%$ obviously would have an influence on some parts of the electricity price. Especially for charges (e. g. UoSC or FIT by EEG), where a cost recovery is necessary, a declining electricity demand from the grid will result in increasing electricity prices, because (constant) total costs have to be distributed among a reduced amount of energy consumption. Taking only UoSC $(6.5 \mathrm{ct} / \mathrm{kWh})$ and EEG surcharge $(6.2 \mathrm{ct} / \mathrm{kWh})$ (BNetzA, 2014) into account, the electricity price would increase from 29.5 to $33.8 \mathrm{ct} / \mathrm{kWh}$. Subsequently, if the current tariff is not changing, all households without selfconsumption will be faced with increasing electricity prices. This could lead to an accelerated market penetration of PV-SBS, as profitability increases. On the other hand, households without possibilities to install or access PV systems (or, more generally, self-generation of electricity) might be discriminated, as they have few options to take countermeasures. But in this context the rolling mechanism of costs for UoSC from highest voltage level down to lowest voltage level, where private customers are located and charged maximum is also of relevance. In the future, this rolling down of costs on the voltage levels will not be adequate any longer, as feed-in on low-voltage levels will further increase and the top-down electricity transportation will be substituted by bidirectional power flows and a higher share of generation and consumption on same voltage level.

One alternative to current UoSC might be to increase the basic charge of electricity and include EEG surcharges and UoSC. This is obvious, as electricity grid operation is associated with a high amount of fixed costs. An increase of the monthly basic charge for power connection is the first option that would charge all households equally, irrespective of the amount of purchased electricity. But in this case, also small households have to pay a comparatively high fixed fee. Furthermore, this thereby reduced electricity price decreases the incentive for energy savings and for the provision of flexible loads (including SBS). In the discussion is also the shift from EEG surcharge to a solution based on taxes (Bardt et al., 2012). This would decrease electricity prices but increase taxes. For PV systems and SBS such a change would reduce profitability (cf. section 4.6).

Another alternative might be to introduce a demand charge. Households are incentivized to decrease load peaks. In this case, households with flexible loads or storage options again have an advantage. Here, peak load-oriented pricing alternatives are feasible (Hayn et al., 2014). The installation of circuit breakers for households with lower load limits (e. g. 16 A or $32 \mathrm{~A}$ ) compared to today is one possibility. They interrupt current flow at overload as applied in France (EdF, 2015).

(3) Looking at the local grid situation, reducing load and feed-in peaks seems to be reasonable to reduce grid extensions and prevent the system costs from increasing further (BMWi, 2014). 
The coming changes of load profiles and the increased load shifting potentials are worth looking at. Dynamic pricing as a demand response measure is already widely discussed in literature (e. g. Faruqui et al., 2014). Time-differentiated dynamic pricing with ToU pricing stimulates load shifting. This is confirmed by field tests with EV (ECOtality and INL, 2013) and also at households (Hillemacher, 2014). As a drawback, the high load shift potential leads to high load peaks in the beginning of offpeak prices. This simultaneousness might even cause grid overload (Paetz et al., 2013). Therefore, the tariff scheme has to be designed carefully. In this context, user acceptance is to be considered. Dütschke and Paetz (2013) conclude that customers are open for dynamic pricing, but simple programs are preferred.

\section{Conclusions and policy implications}

In the context of the German energy transition, a mass market for domestic photovoltaic (PV) roof-top systems was mainly incentivized by the feed-in tariff (FIT) system guaranteed by the Renewable Energy Act (EEG). Due to the decreasing prices for PV systems and a continuous increase of the household electricity price, Germany became one of the first countries, where grid parity was achieved and self-consumption became attractive. These developments change the demand structure, demand quantities, and the load of the local power grid, especially by PV feed-in. Further market developments and decreasing battery costs will make both electric vehicles (EV) and stationary battery systems (SBS) more attractive and, thus, further increase self-consumption and self-generation. Altogether, these developments might be a game changer of electricity provision, as they affect all parts from generation to the demand side and from electricity markets to customer tariffs.

The developed techno-economic optimization model for German households with PV, SBS, and EV allows evaluating the net present values for the PV system and the SBS from the household perspective.

Our results show that with the underlying assumptions PV systems will be profitable in a few years from now even without a guaranteed FIT (NPV average approx. 2,350-4,970 EUR). Even SBS may become economically efficient in the next years (NPV average approx. 625-1,950 EUR) due to decreasing investment costs. Based on these results and the previous discussion (see chapter 5), we support the arguments and German policy of phasing out the funding for PV (EEG) in the coming years instead of discussing adjustments of FIT for PV (e. g. Leepa and Unfried, 2013).

The positive effects of PV-SBS together with EV are the increase of decentralized renewable electricity production (through the profitability by high self-consumption), the increase of flexibility in electricity demand and carbon dioxide reductions. Our results do not show whether these investments in PV-SBS are optimal from the national system perspective like evaluations of Babrowski (2015) or Heffels (2015).

Increasing load shifting potentials and storage capacities make demand side management measures more effective. Our results show extreme changes and a reduction of external procurement of electricity to $48-58 \%$. If these systems enter the mass market, they will not only affect the generation side, but also substantial parts of the electricity price. Based on these aspects, rethinking of cost allocations in the electricity tariff and a search for alternatives are inevitable. This is in line with 
recommendations by Gawel and Purkus (2015), which focus on energy taxation as one significant part of the energy transition process and the aim to gradually reduce allocative tax-induced distortions.

A decline of electricity demand will result in increasing electricity prices for households because of the reallocation of constant costs, such as the use of system charges (UoSC) or charges for remunerations of FIT by EEG. These increasing electricity prices might lead to a disproportionally high burden for customers without flexible loads or self-generation units.

The of UoSC for household customers are mainly integrated into the electricity price (energy charge). Results with an increased fixed fee component (basic charge) are not activating load shifting and should therefore be coupled with a peak-load component (demand charge) which is already applied for industrial customers.

A combination of measures to change electricity tariffs seems to be attractive, as single measures tend to prefer single customer groups and cause new challenges. For example, time-varying prices allow incentivizing load shifting, which could harmonize demand and (central) feed-in, but cause new peak loads. Load limits might be of interest for grid operators to prevent overloads. Therefore, policy makers should initiate measures to further shape the integration of the demand side with respect to all customer groups.

Our optimization model produced results for cost-optimal dimensioning and NPV of PV-SBS systems from the household perspective. Uncertainties of input parameters are only considered by a sensitivity analysis. In reality, the market only has deterministic system sizes and charging is not applied optimal as weather and demand predictions are not perfect. Both reduce the profitability and the effectiveness of policies to support renewable energy integration. Furthermore, this contribution covers the topic from the point of view of a future completely rational acting household. We did not evaluate alternative tariff schemes or components for other customer groups or other stakeholders. As the German energy transition implies changes for all stakeholders, the discussion should be extended to include different objectives and the heterogeneity of stakeholders, including their user acceptance. Connecting renewable energy production with grid limitations and customers' demand flexibilities on both a local and a national level and with respect to all stakeholders remains to be studied in the future.

\section{Acknowledgments}

This research is part of the project iZEUS (01ME12013) which is funded by the German Federal Ministry of Economic Affairs and Energy (BMWi). We are also very grateful for the constructive remarks of two anonymous reviewers.

\section{References}

Agora, 2013. Zusammenhang von Strombörsenpreisen und Endkundenpreisen. Energy Brainpool, on behalf of Agora Energiewende.

Babrowski, S., 2015. Bedarf und Verteilung elektrischer Tagesspeicher im zukünftigen deutschen Energiesystem. Karlsruhe, KIT, PhD thesis, KIT Scientific Publishing.

Babrowski, S., Heinrichs, H., Jochem, P., Fichtner, W., 2014. Load Shift Potential of Electric Vehicles in Europe. J. of Power Sources 255, 283-293. 
Bardt, H., Brügelmann, R., Niehues, J., Schaefer, T., 2012. Alternative Möglichkeiten der steuerlichen Finanzierung der EEG-Kosten - Aufkommens- und Verteilungseffekte, Kurzgutachten des Instituts der deutschen Wirtschaft Köln.

BMU (Bundesministerium für Umwelt, Naturschutz und Reaktorsicherheit; German Federal Ministry for the Environment, Nature Conservation and Nuclear Safety), 2011. Vorbereitung und Begleitung der Erstellung des Erfahrungsberichtes 2011 gemäß § 65 EEG - Vorhaben II c Solare Strahlungsenergie.

BMVBS (Bundesministerium für Verkehr, Bau und Stadtentwicklung; German Federal Ministry for Transport, Building and Urban Development), 2010. Deutsches Mobilitätspanel (MOP). By Institute for Transport Studies (IfV), Karlsruhe Institute of Technology (KIT).

BMWi (Bundesministerium für Wirtschaft und Energie; German Federal Ministry for Economic Affairs and Energy), 2014. Moderne Verteilernetze für Deutschland (Verteilernetzstudie). By EBridge, IAEW and OFFIS.

BMWi (Bundesministerium für Wirtschaft und Energie; German Federal Ministry for Economic Affairs and Energy), 2016. Zahlen und Fakten - Energiedaten - Nationale und Internationale Entwicklung. 12.01.2016.

BNetzA (Bundesnetzagentur; Federal Network Agency for Electricity, Gas, Telecommunications, Post and Railway), 2014. Monitoringbericht 2014.

Bruch, M., Müller, M., 2014. Calculation of the Cost-effectiveness of a PV Battery System. Energy Procedia 46, 262-270.

BSW (Bundesverband Solarwirtschaft; German Solar Association), 2014. Statistische Zahlen der deutschen Solarstrombranche (Photovoltaik).

Cai, D.W., Adlakha,S., Low, S.H., De Martini, P., Mani Chandy, K., 2013. Impact of residential PV adoption on Retail Electricity Rates. Energy Policy 62, 830-843.

Cludius, J., Hermann, H., Matthes, F.C., Graichen, V., 2014. The Merit Order Effect of Wind and Photovoltaic Electricity Generation in Germany 2008-2016 - Estimation and Distributional Implications. Energy Econ. 44, 302-313.

Destatis (German Federal Statistical Office), 2014. Statistical Yearbook 2014.

Dufo-Lopez, R., Bernal-Augustin, J., 2015. Techno-economic analysis of grid-connected battery storage. Appl. Energy 140, 395-404.

Dütschke, E., Paetz, A.G., 2013. Dynamic electricity - Which programs do consumers prefer? Energy Policy 59, 226-234.

DWD (Deutscher Wetterdienst; Germany's National Meteorological Service), 2004. Testreferenzjahre von Deutschland für mittlere und extreme Witterungsverhältnisse TRY.

EdF (Electricité de France), 2015. Electricity Tarif Blue, July 28, 2015, http://residential.edf.com/energy-at-home/offers/electricity/tarif-bleu-56121.html.

ECOtality (Electric Transportation Engineering Corporation), INL (Idaho National Laboratory), 2013. How do PEV owners respond to time-of-use rates while charging EV Project vehicles? The EV Project. 
EEG, 2014. Gesetz für den Ausbau erneuerbarer Energien (Erneuerbare-Energien-Gesetz, EEG 2014). Version of Gesetz zur grundlegenden Reform des Erneuerbaren-Energien-Gesetzes und zur Änderung weiterer Bestimmungen des Energiewirtschaftsrechts, Bundesgesetzblatt Jahrgang 2014, Teil I, 1066. Bundestag (German parliament).

ElNozahy, M.S., Abdel-Galil, T.K., Salama, M.M.A., 2015. Probabilistic ESS sizing and scheduling for improved integration of PHEVs and PV systems in residential distribution systems, in Electr. Power Syst. Res. 125, 55-66.

Erdinc, O., 2014. Economic impacts of small-scale own generating and storage units, and electric vehicles under different demand response strategies for smart households. Appl. Energy 126, $142-$ 150 .

Faruqui, A., Sergici, S., Akaba, L., 2014. The Impact of Dynamic Pricing on Residential and Small Commercial and Industrial Usage: New Experimental Evidence from Connecticut. Energy J. 35, $137-160$

Fuhs, M., 2012. Die Speicher kommen. photovoltaik, 10, 40-49.

Fuhs, M., 2014. Zwei Jahre Speichermarkt und Marktübersicht Batteriespeicher. pv magazine, 2, 3856.

Fuhs, M., 2015. Brauchen wir die Tesla-Batterie? pv magazine Deutschland, Juni, 28-34.

Gawel , E., Purkus, A., 2015. The Role of Energy and Electricity Taxation in the Context of the German Energy Transition, Z. Energiewirtsch. 39, 77-103.

Ghofrani, M., Arabali, A., Ghayekhloo, M., 2014. Optimal charging/discharging of grid-enabled electric vehicles for predictability enhancement of PV generation, in Electr. Power Syst. Res. 117, 134-142.

Giessing, F.-H., 2010. Ein Beitrag zum Kapazitätstarif für die Netznutzung von Standardlastprofilen. Universität Rostock.

Gottwalt, S., Ketter, W., Block, C., Collins, J., Weinhardt, C., 2011. Demand side management - A simulation of household behavior under variable prices. Energy Policy 39, 8163-8174.

Hahn, T., Schönfelder, M., Jochem, J., Heuveline, V., Fichtner, W., 2013. Model-Based Quantification of Load Shift Potentials and Optimized Charging of Electric Vehicles. Smart Grid and Renew. Energy 4, 398-408.

Hayn, M., Bertsch, V., Fichtner, W., 2014. Stromtarife und Technologien im Endkundenmarkt und deren Einfluss auf den Leistungsbedarf von Haushalten aus dem Netz. uwf UmweltWirtschaftsForum 22, 249-255.

Heffels, T., 2015. Kraftwerks- und Speicherbedarf bei hohen Anteilen erneuerbarer Energien. Karlsruhe, KIT, PhD thesis, KIT Scientific Publishing.

Helms, H.; Pehnt, M.; Lambrecht, U.; Liebich, A., 2010. Electric vehicle and plug-in hybrid energy efficiency and life cycle emissions. 18th International Symposium Transport and Air Pollution, June $18^{\text {th }}+19^{\text {th }} 2010$, Dübendorf, Switzerland.

Hillemacher, L., 2014. Lastmanagement mittels dynamischer Strompreissignale bei Haushaltskunden, Karlsruhe, KIT, PhD thesis, KIT Scientific Publishing. 
IEA (International Energy Agency), 2013. Global EV Outlook - Understanding the Electric Vehicle Landscape to 2020 .

IEA (International Energy Agency), 2015. Global EV Outlook 2015.

IE-Leipzig, 2014. Wirtschaftlichkeit Batteriespeicher - Berechnung der Speicherkosten und Darstellung der Wirtschaftlichkeit ausgewählter Batterie-Speichersysteme. Leipziger Institut für Energie on behalf of Redpoint Solar GmbH.

Illing, B., Bretschneider, P., Westermann, D., 2011. Berechnungsansatz für variable Netznutzungsentgelte zum Einfluss auf den Lastverlauf in der Verteilernetzebene. Internationaler ETG-Kongress.

IMK (Institut für Meteorologie und Klimaforschung; Institute of Meteorology and Climate Research), 2014. Measured weather data of the meteorological station on the physics building in Karlsruhe for the years 2008 to 2011, Karlsruhe Institute for Technology (KIT).

ISO 61851, (2012). Electric vehicle conductive charging system - Part 1: General requirements (IEC 61851-1:2010)

Jochem, P., Babrowski, S., Fichtner, W., 2015. Assessing $\mathrm{CO}_{2}$ Emissions of Electric Vehicles in Germany in 2030. Transp. Res. Part A: Policy and Pract. 78, 68-83.

Jochem, P., Kaschub, T., Fichtner, W., 2014. How to Integrate Electric Vehicles in the Future Energy System?, in: Hülsmann, M., Fornahl, D. (Eds.), Evolutionary Paths Towards the Mobility Patterns of the Future, Springer, 243-263.

Kalhammer, F.R., Kopf, B.M., Swan, D.H., Roan, V.P., Walsh, M.P., 2007. Status and Prospects for Zero Emissions Vehicle Technology - Report of the ARB Independent Expert Panel 2007. California Environmental Protection Agency - Air Resources Board.

Kairies, K.-P., Haberschusz, D., van Ouwerkerk, J., Strebel, J., Wessels, O.; Magnor, D., Badeda, J., Sauer, D.U., 2016. Wissenschaftliches Mess- und Evaluierungsprogramm Solarstromspeicher Jahresbericht 2016, Stromspeichermonitoring des Institut für Stromrichtertechnik und Elektrische Antriebe (ISEA), RWTH Aachen.

Kanngiesser, A., 2013. Entwicklung eines generischen Modells zur Einsatzoptimierung von Energiespeichern für die techno-ökonomische Bewertung stationärer Speicheranwendungen, Fakultät für Elektrotechnik und Informationstechnik, Technische Universität Dortmund.

Kaschub, T., Heinrichs, H., Jochem, P., Fichtner, W., 2013. Modeling Load Shifting Potentials of Electric Vehicles. IAEE European Conference 2013, Duesseldorf.

KfW, 2015. KfW-Programm Erneuerbare Energien "Speicher". Kreditanstalt für Wiederaufbau (KfW; German Reconstruction Loan Corporation) and Bundesministerium für Wirtschaft und Energie (BMWi, German Federal Ministry for Economic Affairs and Energy).

Komiyama, R., Fujii, Y., 2014. Assessment of massive integration of photovoltaic system considering rechargeable battery in Japan with high time-resolution optimal power generation mix model. Energy Policy 66, 73-89.

Konstantin, P., 2009. Praxisbuch Energiewirtschaft. Springer Berlin Heidelberg. 
Leepa, C., Unfried, M., 2013. Effects of a cut-off in feed-in tariffs on photovoltaic capacity: Evidence from Germany. Energy Policy 56, 536-542.

Loisel, R., Pasaoglu, G., Thiel, C., 2014. Large-scale deployment of electric vehicles in Germany by 2030: An analysis of grid-to-vehicle and vehicle-to-grid concepts. Energy Policy 65, 432-443.

Lunz, B., Yan, Z., Gerschler, J.B., Sauer, D.U., 2012. Influence of plug-in hybrid electric vehicle charging strategies on charging and battery degradation costs. Energy Policy 46, 511-519.

Lyon, T.P., Michelin, M., Jongejan, A., Leahy, T., 2012. Is 'smart charging' policy for electric vehicles worthwhile? Energy Policy 41, 259-268.

McHenry, M.P., 2012. Are small-scale grid-connected photovoltaic systems a cost-effective policy for lowering electricity bills and reducing carbon emissions? A technical, economic, and carbon emission analysis. Energy Policy 45, 64-72.

Moshövel, J., Kairies, K.-P., Magnor, D., Leuthold, M., Bost, M., Gährs, S., Szczechowicz, E., Cramer, M., Sauer, D.U., 2015. Analysis of the maximal possible grid relief from PV-peak-power impacts by using storage systems for increased self-consumption, in Applied Energy 137, 567-575.

Nykvist, B., Nilsson, M., 2015. Rapidly falling costs of battery packs for electric vehicles. Nat. clim. change 5, 329-332.

Paetz, A.G., Kaschub, T., Jochem, P., Fichtner, W., 2013. Load-Shifting Potentials in Households including Electric Mobility - a Comparison of User Behaviour with Modeling Results. $10^{\text {th }}$ International Conference on European Energy Markets, Stockholm.

Poudineh, R., Jamasb, T., 2014. Distributed generation, storage, demand response and energy efficiency as alternatives to grid capacity enhancement. Energy Policy 67, 222-231.

Quaschning, V., 2013. Regenerative Energiesysteme: Technologie - Berechnung - Simulation, 8th ed. Hanser.

Ratnam, E.L., Weller, S.R., Kellett, C.M., 2015. An optimization-based approach to scheduling residential battery storage with solar PV: Assessing customer benefit. Renew. Energy 75, 123-134.

Rudolf, V., Papastergiou, K.D., 2013. Financial analysis of utility scale photovoltaic plants with battery energy storage. Energy Policy 63, 139-146.

Sakhrami, V., Parsons, J.E., 2010. Electricity Network Tariff Architectures - A Comparison of Four OECD Countries. Center for Energy and Environmental Policy Research (CEEPR).

Sandoval, D., Leibundgut, H., 2014. Introduction of electrical batteries in the operation of LowEx buildings. Energy and Build. 81, 105-114.

Satchwell, A., Mills, A., Barbose, G., 2015. Quantifying the financial impacts of net-metered PV on utilities and ratepayers. Energy Policy 80, 133-144.

Schieferdecker, B., Fünfgeld, C., Meyer, H., Adam, T., 1999. Repräsentative VDEW-Lastprofile, VDEW-Materialien M-28/1999, Frankfurt.

Schmiegel, A.U., 2014. Die Leiden des Alters. pv magazine, 2014, 1(March), 12-16. 
Schmiegel, A.U., Kleine, A., 2014. Optimized Operation Strategies for PV Storages Systems Yield Limitations, Optimized Battery Configuration and the Benefit of a Perfect Forecast. Energy Procedia 46, 104-113.

Tesla, 2015. PowerWall Tesla Home Battery, http://www.teslamotors.com/powerwall, May 8, 2015.

Thiel, C., Schmidt, J., Van Zyl, A., Schmid, E., 2014. Cost and well-to-wheel implications of the vehicle fleet $\mathrm{CO} 2$ emission regulation in the European Union. Transp. Res. Part A: Policy and Pract. 63, 25-42.

Tveten, A.G., Bolkesjö, T.F., Martinsen, T., Hvarnes, H., 2013. Solar feed-in tariffs and the merit order effect: A study of the German electricity market. Energy Policy 61, 761-770.

UBA (Umweltbundesamt;German Federal Environment Agency), 2015. Entwicklung der spezifischen Kohlendioxid-Emissionen des deutschen Strommix in den Jahren 1990 bis 2014. Clim. change 09/2015.

United Nations, 2015. Adoption of the Paris agreement - Draft decision -/CP.21, Conference of the Parties, Twenty-first session, Paris, 30 November to 11 December 2015.

Weiller, C., 2011. Plug-in hybrid electric vehicle impacts on hourly electricity demand in the United States. Energy Policy 39, 3766-3778.

Weniger, J., Tjaden, T., Quaschning, V., 2014. Sizing of Residential PV Battery Systems. Energy Procedia 46, 78-87.

Wirth, H., 2015. Recent Facts about Photovoltaics in Germany. Fraunhofer Institute for Solar Energy Systems ISE, May 19, 2015.

Yoza, A., Yona, A., Senjyu, T., Funabashi, T., 2014. Optimal capacity and expansion planning methodology of PV and battery in smart house. Renew. Energy 69, 25-33.

Zhao, J., Kucuksari, S., Mazhari, E., Son, Y.J., 2013. Integrated analysis of high-penetration PV and PHEV with energy storage and demand response. Appl. Energy 112, 35-51.

Zucker, A., Hinchliffe, T., 2014. Optimum sizing of PV-attached electricity storage according to power market signals - A case study for Germany and Italy. Appl. Energy 127, 141-155. 